\title{
Child Health across the Rural-Urban Spectrum
}

\author{
Hannah Ameye ${ }^{\mathrm{a}^{*}}$ and Joachim De Weerdt ${ }^{\mathrm{a}, \mathrm{b}}$
}

\begin{abstract}
It is widely known that in sub-Saharan Africa child health outcomes are better in urban than in rural areas. Less is known about how they evolve across different levels of urbanization. We use nighttime light intensity as a continuous measure of urbanization and reveal large differences both between and within urban agglomerations. We then link stunting levels recorded in recent Demographic and Health Surveys (DHS) for 40,000 children from ten East African countries, to local nighttime light intensity to document how child health evolves across the urban spectrum. In all ten countries child stunting improves rapidly at low levels of urbanization. At the highest levels of urbanization two different trends can be discerned. For one group of countries the improvements level off, for the other group they deteriorate. The deterioration is especially notable for children from the two richest wealth quartiles. Investigating probable proximate causes of these patterns we track how a number of determinants of child health vary with urbanization. We find that healthcare access and sanitation improve with urbanization and so likely contribute to the initial improvements in child stunting. Child feeding practices, such as meal frequency, consumption of iron-rich foods and diet diversity, also improve initially but deteriorate at the highest levels of urbanization, possibly explaining why child health outcomes do not continue to improve or even worsen in the most economically active urban areas.
\end{abstract}

Keywords: Child Health, Stunting, Urbanization, East Africa

We acknowledge funding from Excellence of Science (EOS) Research Project 30784531 at the Research Foundation - Flanders (FWO) and the KU Leuven Methusalem Program. We greatly benefitted from comments by the editor, three anonymous referees, John Gibson and Andrew McKay, as well as from seminar participants at LICOS, KU Leuven, ICAE 2018, CSAE 2019 and NCDE 2019.

${ }^{a}$ LICOS Centre for Institutions and Economic Performance, KU Leuven, Waaistraat 6 bus 3511, 3000 Leuven, Belgium

${ }^{\mathrm{b}}$ IOB, Institute of Development Policy, University of Antwerp, Prinsstraat 13, 2000 Antwerpen, Belgium

* Corresponding author hannah.ameye@ kuleuven.be, +3216328664 


\section{INTRODUCTION}

Developing countries are urbanizing rapidly. Nowhere is this phenomenon as pronounced as in sub-Saharan Africa (SSA), where annual urban growth rates have been around 3.5\% for the past two decades and projections expect this trend to continue until 2050 (UN Habitat, 2014). This demographic shift over time from a primarily rural- to a primarily urban-based population will have profound implications across many dimensions of life. This paper looks at one such dimension, child health.

It is well-documented that children living in urban areas in developing countries score, on average, better on a range of health outcomes compared to children in rural areas (e.g. Van de Poel et al., 2007; Firestone et al., 2011). The main outcome of interest in this paper is the prevalence of child stunting, which is widely used as an indicator of adverse nutritional and health outcomes among this population group. Stunting can lead to an array of cognitive and physical problems, more severe illnesses and in some cases premature death (Peeling \& Smart 1994; Pollitt, 1995; Grantham-McGregor et al., 2000; Berkman et al., 2002). This in turn leads to educational difficulties (Lozoff et al., 2000; Glewwe et al., 2001; Caulfield et al., 2006; Luo et al., 2012), lower future incomes (Bobonis et al., 2006; Halterman et al., 2001), increased health costs (Shorr et al., 2008) and decreased life expectancies, thus affecting a region's economic climate.

Research has shown that stunting is more prevalent in rural compared to urban areas (Von Braun, 1993; Menon et al., 2000; Smith et al., 2005; Amare et al., 2018). ${ }^{1}$ Some work explores heterogeneity in rural areas. Using data on 23 sub-Saharan countries Headey et al. (2018) find that children in rural communities are more likely to be stunted and have worse dietary outcomes

\footnotetext{
${ }^{1}$ Urban areas also perform better on an array of other health indicators. Some studies find wasting, or an inappropriate weight-for-height, to be less common in urban areas (Sastry, 1997), however not all studies find a clear difference in this measure (Smith et al., 2005; Amare et al., 2018). Children are also more likely to be underweight in rural regions, indicated by a lower weight-for-age (Ruel et al., 1998). Anaemia is also more common in rural compared to urban areas in Bangladesh and Ghana (Ahmed, 2000; Ronald et al., 2006).
} 
compared to children in urban communities, with children living in more remote rural areas experiencing only a small nutritional penalty.

That child health is better in urban areas is cause for optimism in an urbanizing Africa. But this gives little guidance to policy makers needing to decide on urban investments and, at the margin, which kind of urbanization to promote in their countries. This is an important lacuna, not in the least because choices made now will lock countries into a specific urbanization model for decades to come. ${ }^{2}$

Furthermore it is a priori unclear which trend, if any, child health is expected to follow across the urban continuum. Urbanization has been identified as an important driver of the "nutrition transition", through which dietary patterns and levels of physical activity are undergoing profound changes. While food insecurity and undernutrition are more common in rural areas, urban areas suffer more from dietary excess, which, exacerbated by sedentary lifestyles, leads to higher levels of obesity and an elevated prevalence of nutrition-related non-communicable diseases (see for example Doak et al., 2005; Hawkes, 2008; Popkin, 1999; 2001). Cockx et al. (2018) discern a shift away from traditional staples towards more conveniently consumed, high-sugar or prepared foods when rural dwellers move to an urban environment in Tanzania, an effect that is more pronounced for those moving to cities compared to those moving to smaller towns. These findings indicate that diet quality can be highly varied between different types of urban areas. Calorie requirements may be fulfilled, yet micronutrient deficiencies may still be prominent.

High (and rising) urban incomes play an important role in mediating these effects (Hirvonen, 2016), but could be associated with a host of other pathways through which child health is affected. Increased income instigates higher opportunity costs of staying at home which creates a

\footnotetext{
${ }^{2}$ Recent research has highlighted one interesting dimension in which this choice needs to be made: whether to invest in urbanization through large cities or through small towns (Christiaensen et al., 2013; Ingelaere et al., 2018). Secondary towns have come out quite favourably in this strand of the literature. Secondary towns are found to be positively associated with economic growth (Dorosh \& Thurlow, 2013), inclusive growth (Christiaensen \& Todo, 2014), employment opportunities for the poor (Glasser \& Raich., 2008), poverty reduction (Christiaensen et al., 2017; Barrett et al., 2017; Mellor, 2017; Christiaensen et al. 2019; Kanbur et al., 2019) and creating opportunities in the surrounding rural areas (Berdegue et al., 2014, Vandercasteelen et al., 2017).
} 
trade-off with parental time in caring for children. The opportunity cost of staying at home may be largest in the most urbanized areas. The greater consumption of processed and prepared foods in urban areas has been linked to the opportunity cost of women's time (Atkinson, 1992; Tinker, 1997), especially as consumers perceiving time-scarcity try to reduce time intensive household tasks, such as cooking (Celnik et al., 2012). Indeed, Kulwa et al. (2006) find a significant negative correlation between height-for-age z-scores of children and the number of hours per day mothers worked outside the home. Add to this that people tend to work far from home (Ruel et al., 2008) and that large agglomerations suffer from traffic jams and long commutes (Henderson, 2002). All these factors may influence child care and nutritional practices.

Finally there are large differences in supply-side environments between rural and urban regions, and across various types of urban centres, with diverging access to water, sanitation and healthcare. Healthcare and other social facilities are generally more readily available in urban regions (UNCHS, 2001; Montgomery et al., 2013). Nevertheless, the soar in urbanization in subSaharan Africa may not have been given adequate time to provide sufficient sanitation and livelihood opportunities (Fotso, 2007). Clean water and appropriate waste disposal also experience further pressures from a rapidly growing urban population (Ruel et al., 2008; Crush et al., 2011). It is generally believed that healthcare and sanitation conditions are better in urban compared to rural regions yet these may be affected negatively by increasing migration. There is still no clear consensus on how cities of various magnitudes impact health institutions and sanitation.

Very little insight is given into how this plays out empirically as throughout the health and nutrition literature urbanization is usually observed and analysed as a binary construct, with a simple rural-urban classification. Our paper will link Demographic and Health Survey (DHS) data on 40,000 children, from ten countries in East Africa to satellite data of nighttime lights. Nighttime light data has been used to measure urbanization as light intensity increases from rural to more urbanized areas (Henderson et al., 2003; Burchfield et al., 2006; Sutton et al., 2010; Zhang \& Seto, 2011; Donaldson \& Storeygard, 2016). There are a number of advantages to nighttime 
lights. The first is that they provide a plausible continuous measure of the degree of urbanization and economic activity. Secondly, they provide a definition of urbanization that is consistent across different countries, something which administrative definitions cannot hope to do. Thirdly, as we will show, there is quite some variation within urban areas with respect to the degree of nightlight emitted.

In a paper closely related to ours, Amare et al. (2018) identify that child nutritional outcomes improve and then level off as nightlight increases in Nigeria. Our study extends this work in three important ways. First, we expand the geographical scope to ten different countries in East Africa to test whether the patterns observed in Nigeria hold in other sub-Saharan African nations. Secondly, we enrich the nightlight data with population data on each urban area, allowing us to explore how population size and nightlights interact. Thirdly, we attempt to provide some evidence on the proximate drivers of these patterns by looking at trends in health inputs, maternal care, feeding practices and wealth across the urban spectrum.

We find that child stunting, first improves and then worsens at the highest levels of nighttime light. However, there are substantial disparities between countries. We identify three groups of countries, each following a specific trajectory. The first group, including countries like Burundi and Zimbabwe, do not have any nighttime light values in the upper ranges. Here we simply observe a linear downward trend, similar to all other countries across this area of support. The second group, presenting the most common trajectory, finds that stunting first decreases and then levels off as nighttime light intensity increases. Lastly, two countries, namely Kenya and Zambia, follow the overall evolution found for East Africa, where stunting first decreases across the lower ranges of nighttime light and then increases again at the highest levels of nighttime light.

We then use a new dataset from Africapolis (2018) to obtain population estimates and identify city types for each urban agglomeration in our data. Nighttime lights vary both within agglomerations and across agglomerations of similar sizes, giving us the necessary variation to disentangle the effect of nighttime lights from that of population size. We find that the increase in child stunting in the brightest areas comes from the largest cities of over 1 million people. 
We then look at plausible mechanisms through which these effects take place. While there is no source of exogenous variation available to identify the effects, we gain insights from the extensive literature on child health to see which well-established determinants of child health evolve similarly with urbanization. First, we consider health inputs such as sanitation, clean water and access to healthcare, which have been shown to contribute greatly to child health (Smith, 1999; Marmot, 2006). Second, we look at infant and young child feeding practices, also important determinants of child nutrition and health (Black et al., 2008; WHO, 2009). Sanitation and healthcare access consistently improve with nighttime lights, which likely contributes to the decrease in child stunting but does not explain the upturn at the highest levels of urbanization. Child feeding practices, however, follow the same initial improvement, but then deteriorate at the highest nightlight levels, mirroring the rise in child stunting in these areas.

While healthcare access, sanitation and child feeding practices are important determinants of child health, they remain proximate causes, which may, in themselves, have deeper root causes. However, as their importance for child health has been clearly established in the health literature, we are quite confident that they are part of the causal chain. We also look at how maternal and household characteristics vary across the urban spectrum and weigh up to what extent increasing wealth and other changes could account for the observed patterns. We find that the deterioration in child stunting rates is particularly pronounced for the highest wealth quartiles.

Section 2 of this paper will describe the data used in our analysis, section 3 presents the main results and section 4 discusses pathways. Section 5 explores heterogeneity across these pathways and section 6 concludes.

\section{DATA}

\subsection{Health outcomes and pathways}

The data used in this paper come from the Demographic and Health Surveys phase VI and VII (DHS). We use child health outcomes, healthcare access and sanitation indicators and nutritional 
inputs for 40,324 children between 24 and 59 months old in ten countries in East Africa ${ }^{3}$. Following recommendations by Alderman and Heady (2018), we exclude children younger than 24 months as any potentially harmful effects on height will not have manifested completely before this age, potentially leading to attenuated coefficients. Our primary health outcome is child stunting, which we define as a child having a height-for-age z-score (HAZ) two standard deviations below their reference group. Stunting indicates that a child has been unable to reach their full potential both physically and mentally due to chronic malnutrition.

The DHS also provide information on at least three direct determinants of child health: sanitation, healthcare access and nutritional inputs. First, for sanitation we know whether the household members have access to clean water ${ }^{4}$, whether they have a proper toilet ${ }^{5}$ available, and whether they dispose of child waste properly ${ }^{6}$. Second, for health facility access we know whether or not the respondent reports the distance to a health facility to be an impediment.

The third health determinant, feeding practices, are calculated based on the World Health Organization's (2008) infant and young child feeding practices (from hereon called feeding practices). These feeding practices are key indicators identifying whether babies and young children are receiving a fulfilling diet. Proper feeding improves child survival as well as optimal physical and mental development, especially during the crucial years between birth and 2 years of age. Current global statistics on proper feeding practices (UNICEF, 2018) are striking with only 2 out of 5 children exclusively breastfed below the age of 6 months and less than $75 \%$ of children being breastfed over the age of one. Numbers are even more concerning when it comes to solid food consumption with only 1 out of 2 children receiving the minimum meal frequency

\footnotetext{
${ }^{3}$ Burundi, Kenya, Ethiopia, Malawi, Mozambique, Rwanda, Tanzania, Uganda, Zambia and Zimbabwe ${ }^{4}$ Access to clean drinking water is defined as drinking water directly piped into the dwelling or plot, coming from a public tap or tube well, a tanker truck or bottled water. This excludes all water sources that are not regulated or protected.

${ }^{5}$ Access to a proper toilet is defined as having access to a toilet with a flushing system or a ventilated improved latrine. This excludes other types of public latrines or no facility use.

${ }^{6}$ Disposing of child waste properly is defined as flushing waste down a toilet or latrine or thrown into the garbage. This excludes child waste being buried or not disposed of.
} 
and only $25 \%$ of children reaching the minimum diet diversity required. Concentration on these feeding practices is therefore imperative in nutrition and child health research.

We use four indicators to measure feeding practices: a diet diversity score (Hirvonen, 2016), consumption of iron-rich foods, minimum meal frequency and continued breastfeeding after 1 years old. Importantly, DHS only collects food consumption data for the youngest child of the mother, conditional on the child having been born about 2 years prior to the survey. Due to our focus on children between 24-59 months old, this leaves few relevant data points on feeding practices for our sample of interest. To circumvent this we calculate average feeding practices at the cluster level, reflecting the typical feeding practices employed in the direct environment of the children in our sample.

We first calculate the diet diversity score, iron-rich food consumption and minimum meal frequency for the eligible youngest child of the mother. The diet diversity score, iron-rich food consumption and minimum meal frequency are measured for children between 6 and 23 months old. The diet diversity score states how many food groups were consumed from seven recommended food groups: grains, roots and tubers, legumes and nuts, dairy products, flesh foods, eggs, vitamin A-rich fruits and vegetables, and other fruits and vegetables (WHO, 2008). Ironrich food consumption states whether the child received an iron-rich food the previous day. Minimum meal frequency states whether an infant received the minimum required meals according to their age ${ }^{7}$. We extrapolate these indicators to all children in the household to create feeding practice indicators at the household level. Then, we take cluster level averages for each indicator, which will be used in our analysis. Continued breastfeeding is derived from data on the duration of breastfeeding. This includes whether the child is older than 12 months and duration of breastfeeding was over 12 months or whether the mother is still currently breastfeeding and

\footnotetext{
${ }^{7}$ Minimum meals are defined as 2 meals for breastfed infants between 6-8 months, 3 meals for breastfed children between 9-23 months and 4 meals for non-breastfed children between 6-23 months.
} 
the child is older than 12 months. We then also take the average continued breastfeeding at the cluster level.

We further look at data on maternal education and earnings in cash, to gauge whether opportunity costs for women could adversely affect child feeding and therefore increase child stunting prevalence. A lower maternal education can also negatively impact child nutrition and health (Christiaensen \& Alderman, 2004; Choudhury et al., 2019). To capture the influence of wealth, we use DHS data on asset ownership to construct a wealth index, allowing for cross-country wealth comparability. Following recommendations by Booysen et al. (2008), Traissac \& MartinPrevel (2012) and Ezzrari \& Verme (2012) we use durable consumption goods to derive a wealth index using a multiple correspondence analysis. This method is most effective when using categorical instead of continuous variables. Our index is based on whether a household has electricity, owns a radio, television, refrigerator, bicycle, motorcycle, car/truck, has a concrete or tile floor, has at least a metal roof, has cement walls and uses non-wood cooking fuel. Access to water and toilet facilities are excluded as these will be captured separately through our healthcare and sanitation variables. The index is then normalized.

Finally, we complement the child stunting and pathway data with data on wasting and anaemia. Wasting is defined as having a measured weight-for-height z-score (WHZ) two standard deviations below the reference group median. Wasting is the consequence of undernutrition or severe disease, resulting in considerable weight loss. Anaemia constitutes a loss of red blood cells in the blood, a decrease in haemoglobin in the blood or a reduced ability for the blood to carry oxygen. We create a dummy for whether the child is anaemic or not from the DHS provided data on child anaemia levels.

\subsection{Nighttime lights}

In order to establish the relationship between child health and urbanization, we use satellite nighttime light data as a proxy for urbanization. Recent studies focus on continuous and disaggregated indexes capturing micro-level variations due to the urbanization process (Van de 
Poel et al., 2012). Nighttime light data has the ability to capture urbanization as light intensity increases from rural to urban areas (Henderson et al., 2003; Sutton et al., 2010; Donaldson \& Storeygard, 2016). A study by Zhang \& Seto (2013) furthermore finds that nighttime lights are 93\% accurate in predicting urban clusters, with the main issue being over-glow, now corrected for in recent data. Nighttime lights are also highly correlated with economic activity (Henderson et al., 2012), population (Sutton et al., 2003) and built environment (Lu et al., 2008). A particular advantage is that we can distinguish between various types of urban areas and between different parts of the same urban agglomeration.

The nightlight data used in this paper stems from the Visible Infrared Imaging Radiometer Suite (VIIRS) Day/Night Band (DNB), collected jointly by NASA and the NOAA. The VIIRS DNB data provide several advantages to the previously used Defense Meteorological Satellite Program (DMSP) Operational Linescan System (OLS) data. There is a significant reduction in pixel footprint, lower detection limits, finer quantization, wider dynamic range and inflight calibration (Elvidge et al, 2013). The raw nightlight data is calibrated into units of average radiances in $\mathrm{nW}$ $\mathrm{cm}^{-2} \mathrm{sr}^{-1}$. The Demographic and Health Surveys include a composite of the VIIRS nightlight data in their geo-spatial dataset, which will be used in this paper. Each DHS cluster is represented by an average nighttime light number, calculated by averaging a $2 \mathrm{~km}$ radius in urban areas and a $10 \mathrm{~km}$ radius in rural areas. ${ }^{8}$

The nightlight values for our selection of countries range from 0 to 53.83. However, even for urban regions (defined by Africapolis) the raw nightlight data is severely skewed to the left, as observed in Figure A1, panel 1. 95\% of the urban observations are found below a nightlight of 25.39. To smooth the distribution we use the inverse hyperbolic sine (IHS) transformation. ${ }^{9}$ After applying this transformation we see the nightlight data is more evenly distributed and continuous, with a range from 0 to 4.68 (Figure A1, panel 2).

\footnotetext{
${ }^{8}$ DHS delineation for rural and urban areas is used here.

${ }^{9} \mathrm{~A} \log$ transformation would have been an alternative. The advantage of the IHS transformation is that IHS is defined for zero values (Ravallion, 2017), which is important in the case of our large rural sample living in areas with a nighttime light of 0 .
} 


\subsection{Urban population size}

Figure 1 | Nighttime light projections for East Africa
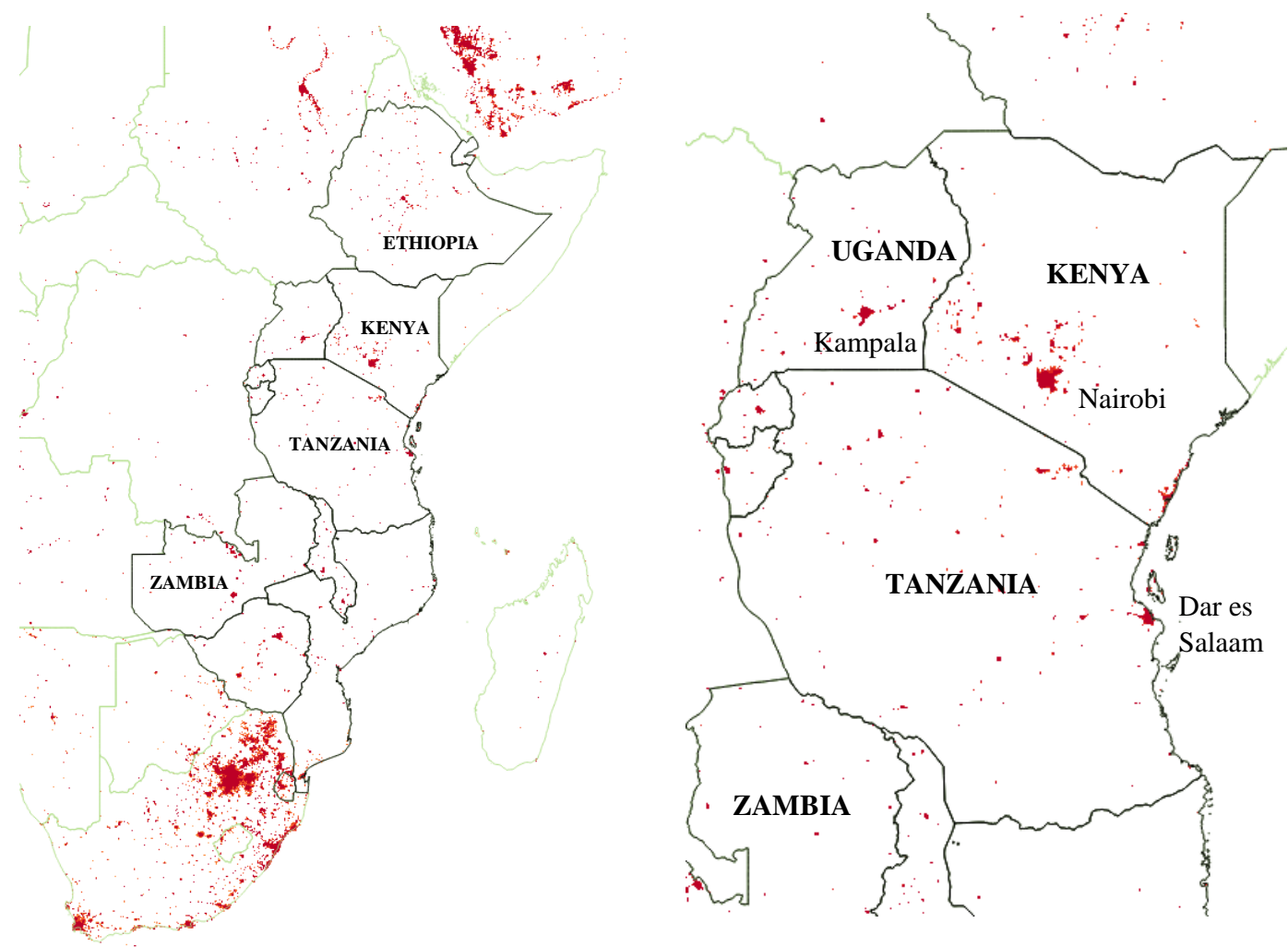

Source: NOAA nighttime light observations for East Africa.

Note: Nighttime light brightness is maximized to show contrast between rural and urban regions in East Africa.

Figure 1 presents a visual overview of the nightlights in our sample. It is observed that capital cities, such as Nairobi and Kampala, and other large cities, like Dar es Salaam, are most illuminated. However, this does not mean that these cities are brightly lit in a spatially uniform way. Figure 2 shows the nighttime light distributions of the most populous city in each of the ten countries in our sample. ${ }^{10}$ In places like Lusaka and Maputo there are no truly dark areas discernible, but in Nairobi, Dar es Salaam and Kampala the distribution reaches all the way to the lowest nighttime lights. This illustrates that even if population and nighttime lights are highly correlated, they do not portray the same aspects of the urbanization process. One advantage of nighttime lights over population data is its high spatial resolution. Whereas population data represent a single number for the whole city, nighttime lights inform us about disparities within a

\footnotetext{
${ }^{10}$ The nighttime light distributions are derived from the DHS sample in each location.
} 
single city and across cities of similar sizes. Such disparities can be quite substantial, as shown in Figure 2.

Figure 2 | Nighttime light distribution for 10 most populous cities
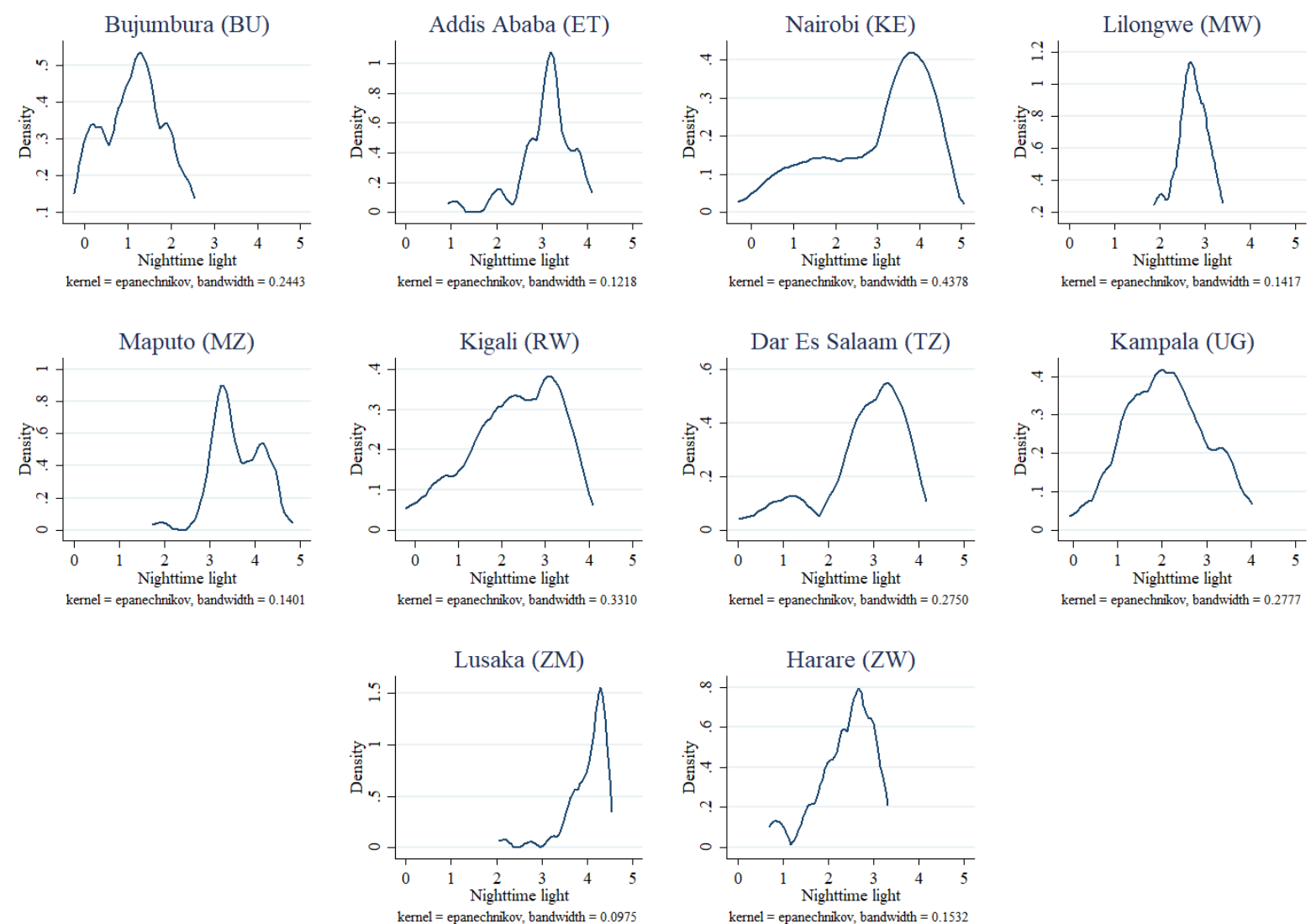

Source: 2015 DHS geophysical data for Burundi, Kenya, Ethiopia, Malawi, Mozambique, Rwanda, Tanzania, Uganda, Zambia and Zimbabwe. Africapolis (2018) population data. $N=40,324$

We bring urban population size data into our analysis by mapping all DHS clusters to the nearest urban agglomerations identified in Africapolis (2018). Due to DHS displacements, we use a 5km buffer to determine whether a DHS cluster is found in an urban region. This cluster is then assigned the matching Africapolis data. Africapolis agglomerations are defined based on a spatial approach applying both a physical element (built-up area) and a demographic element (more than 10,000 inhabitants). An urban area is identified by combining satellite and aerial imagery with official demographic data from censuses and other cartographic sources. Africapolis provides estimates of total population and total built-up area. Using this data, it is useful to categorize the regions in our sample into 4 different groups: rural, small towns (ST) with a population under 
100,000, big towns (BT) with a population between 100,000 and 1,000,000 and cities with a population over 1 million (Table 1, panel A). This gives an idea of the size of the urban areas in our analysis.

Table 1 | Key statistics per population category and nightlight category

\begin{tabular}{l|rrrrr}
\hline & $\begin{array}{c}\text { Average } \\
\text { population }\end{array}$ & $\begin{array}{c}\text { 1st percentile } \\
\text { nightlight } \\
\text { value }\end{array}$ & $\begin{array}{c}\text { Average } \\
\text { nightlight }\end{array}$ & $\begin{array}{c}\text { 99th percentile } \\
\text { nightlight } \\
\text { value }\end{array}$ & $\begin{array}{r}\text { \% children } \\
\text { stunted }\end{array}$ \\
\hline Panel A: & & & & & \\
Rural & & 0 & 0.06 & 1.80 & 43.29 \\
Small town (<100k) & 44767 & 0 & 0.87 & 3.10 & 31.81 \\
Big town (100k-1m) & 343277 & 0 & 1.80 & 3.62 & 29.12 \\
City (>1m) & 2937511 & 0.30 & 3.11 & 4.52 & 23.10 \\
\hline Panel B: & & & & & 41.34 \\
Dark $(0-1.80)$ & 245927 & 0 & 0.15 & 1.80 & 25.46 \\
Medium $(1.80-3.62)$ & 1127323 & 1.82 & 2.61 & 3.62 & 30.58 \\
Bright $(>3.62)$ & 2837623 & 3.63 & 4.07 & 4.68 & \\
\hline
\end{tabular}

Another useful grouping is to separate the nighttime light values into three bins representing dark, medium and bright areas (Table 1, panel B). From Table 1, panel A, we can see that the $99^{\text {th }}$ percentile of nightlight values in rural areas is 1.80 , which we use as the cut-off value for dark areas. This means that (almost) all rural areas fall into the dark category of nighttime lights. But, as we saw in Figure 2, plenty of large cities also have areas categorized as dark. This is also evident from the average population size of dark areas, which falls at about 250,000 people (Table 1, panel B), much higher than an Africapolis defined rural area of less than 10,000 people.

Another natural cut-off is the $99^{\text {th }}$ percentile of the nightlight values for big towns (with a population of $100 \mathrm{k}-1 \mathrm{~m}$ ), which is 3.62 (Table 1). Nightlight values above this occur (nearly) only in the very largest cities with over 1 million people. We call this category bright. Table 1 shows that although cities have a relatively high nightlight value, at on average 3.11 (Table 1 , panel A), this value is much lower than when only observing the brightest regions in our sample, with an average nighttime light of 4.07 (Table 1, panel B).

Finally, we can combine population and nighttime light data to create the following combined bins: rural dark, small town dark, small town medium light, big town dark, big town medium 
light, city dark, city medium light and city bright. Table 2 shows how the sample of 40,324 children is spread across these 8 bins.

Table $2 \mid$ Key statistics per combined population and nightlight category

\begin{tabular}{llccrr}
\hline \multirow{2}{*}{ Urban classification } & Nightlight classification & $\begin{array}{c}\text { Average nightlight } \\
\text { (s.d.) }\end{array}$ & $\mathrm{N}$ & \% observations & $\begin{array}{r}\text { \% children } \\
\text { stunted }\end{array}$ \\
\hline Rural & Dark & $0.06(0.25)$ & 29750 & 73.78 & 43.29 \\
Small town & Dark & $0.78(0.57)$ & 3612 & 8.96 & 32.2 \\
& Medium & $1.05(1.14)$ & 1927 & 4.78 & 31.09 \\
Big town & Dark & $0.78(0.60)$ & 1332 & 3.3 & 28.53 \\
& Medium & $2.61(0.50)$ & 1651 & 4.09 & 29.56 \\
City & Dark & $1.13(0.49)$ & 196 & 0.49 & 25.51 \\
& Medium & $2.89(0.47)$ & 1184 & 2.94 & 18.58 \\
& Bright & $4.08(0.26)$ & 672 & 1.67 & 30.36 \\
\hline Total & & & 40324 & 100 & \\
\hline
\end{tabular}

3. Urbanization and child health

\subsection{Main result}

Table 1, panel A, shows that child stunting levels go down as we move from rural areas, to small and big towns, to large cities. More surprisingly, perhaps, is that Table 1, panel B, shows there is no such downward trend across nighttime lights. Here the darkest areas have the highest stunting levels at $41.34 \%$, but medium lit areas have lower stunting levels $(25.46 \%)$ than the brightest areas $(30.58 \%)$.

To formalize the descriptive statistics depicted in Table 1, panel B, we use nonparametric and unconditional regressions to characterize the relationship between urbanization, proxied by nighttime light, and child stunting. Figure 3 displays the probability that a child is stunted across the spectrum of urbanization. Child stunting decreases with nighttime lights on the darker lefthand side of the distribution, but then increases again on the brighter right-hand side of the distribution, creating a U-shaped evolution. The two vertical lines show the $99^{\text {th }}$ percentile cutoff values for rural areas and big towns, beyond which we can be sure there are virtually no rural areas and no big or small towns, respectively. We see that the downward sloping part of the graph occurs at nighttime light values typical in rural areas, the lowest levels occur at nighttime light 
values typical for towns and some city areas, while the upward sloping section of the graph is restricted to nighttime lights values that occur only in large cities.

As was clear from Section 2, towns and cities also have many darker areas. It is therefore informative to repeat the figure excluding rural observations (clusters with less than 10,000 people, defined by Africapolis). We do this in Figure A2 (Appendix), where the U-shaped curve is maintained for children living in urban regions. Even within urban areas child stunting first improves and then worsens with nighttime lights.

Figure 3 | Polynomial association between the probability a child is stunted and nighttime lights

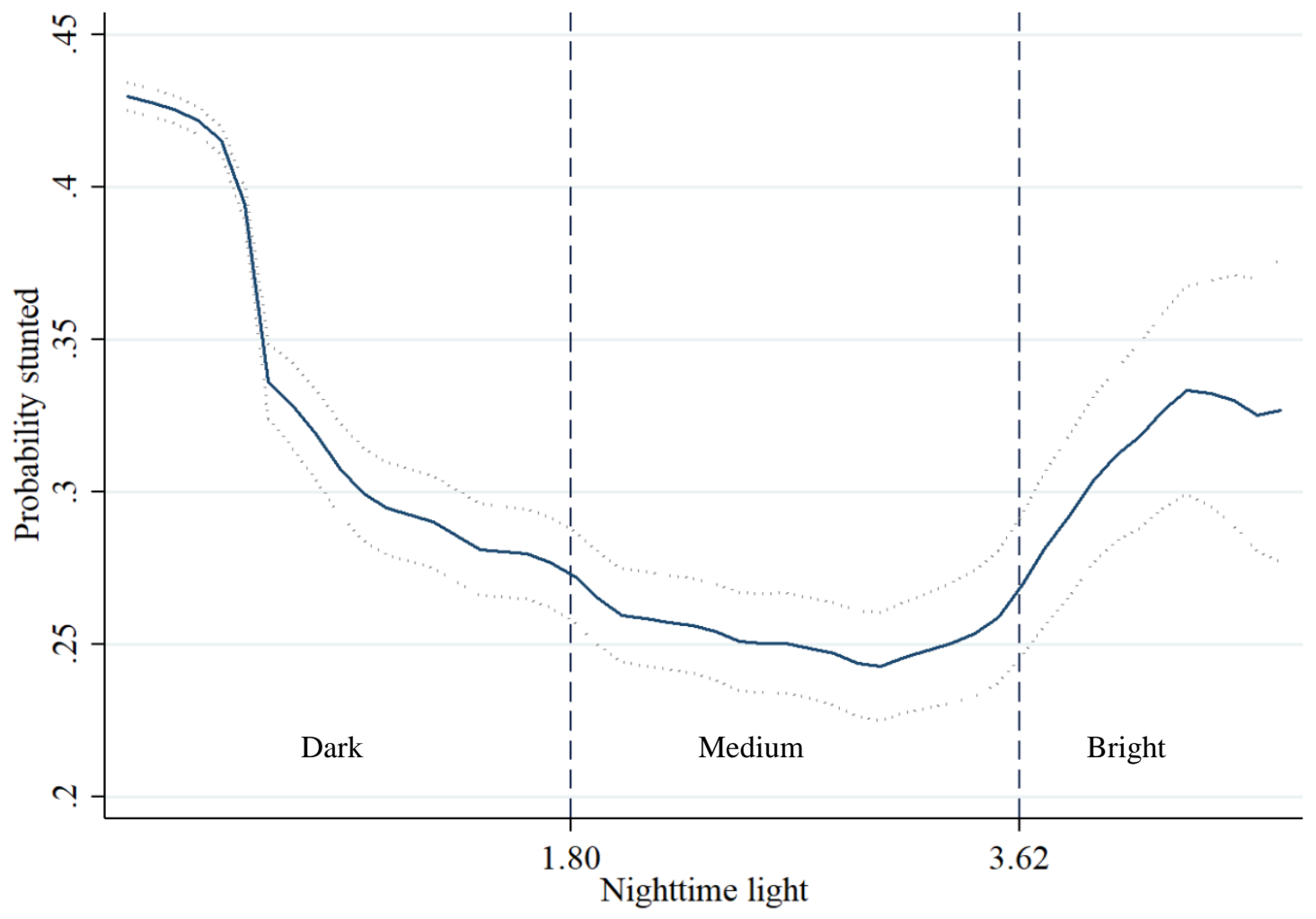

Source: 2015 DHS data for Burundi, Kenya, Ethiopia, Malawi, Mozambique, Rwanda, Tanzania, Uganda, Zambia and Zimbabwe.

Note: The nonparametric regressions are estimated through an Epanechnikov kernel function using a rule-of-thumb bandwidth estimator. The dotted lines around the plot represent the $90 \%$ confidence interval. The y-axes do not start at zero for better rendition of the graph. $N=40,324$

In Table 3, column 1, we show the results from a linear probability model explaining whether or not a child is stunted on the nighttime light categories delineated in Figure 3. In panel A we see that stunting levels are 16 percentage points higher in dark areas compared to medium lit and bright areas. In panel B we see that the brightest areas have stunting levels that are 8 percentage 
points higher than the medium lit areas and 9 percentage points lower than the dark areas, confirming the U-shape in Figure 3.

\subsection{Urban heterogeneity - population size}

Population size is a commonly used proxy for city size. The correlation between urban population and emitted nightlights is positive, but not perfect. Two equally bright areas may be located in urban agglomerations of very different sizes. Similarly, within the same urban agglomeration there will be variation in the intensity of light across space.

In Table 1, panel A, we see that child stunting decreases as population increases. Rural areas have an average child stunting rate of $43.29 \%$. These levels are lower for small and big towns, at $31.81 \%$ and $29.12 \%$ respectively. Cities have the lowest levels of child stunting, at $23.10 \%$. In the first panel of Figure 4, we regress a dummy indicating that a child is stunted on the population size categories from Table 1, panel A. The omitted category in this regression is cities ${ }^{11}$. Confirming the observations from our descriptive statistics in Table 1, we find that child stunting decreases gradually with population size and children living in cities are least likely to be stunted (also found from the polynomial association between child stunting and population size in Figure A3, Appendix).

Conversely, Table 1, panel B, shows that child stunting is lowest in medium-lit regions, at $25.46 \%$ compared to $41.34 \%$ in dark areas and $30.58 \%$ in bright areas. This finding is formalised in the second panel of Figure 4, where bright regions fare better than dark regions but worse than medium-lit regions. Combining both population and nightlight categorizations, Table 2 shows that child stunting is highest in rural, dark regions, at on average $43 \%$. Dark regions also have the highest stunting levels in small and big towns. However, in cities, the brightest regions have the highest prevalence of child stunting, at about $31 \%$, compared to $28 \%$ in dark city regions and $19 \%$ in medium lit city regions. Medium-lit city regions have the lowest overall levels of child stunting. We use these same combined population and nightlight categories in the third panel of Figure 4

\footnotetext{
11 Throughout the analysis we will use the most populous and/or bright areas as the omitted category.
} 
and regress child stunting levels on the interacted dummies, using the bright city regions as the omitted category. We see that medium lit areas in cities have the most favourable child stunting outcomes, suggesting that the upward sloping section of the U-shape in Figure 3 is primarily driven by worse child health outcomes in the brightest areas of cities.

Figure 4 | Probability a child is stunted across population and nightlight categories
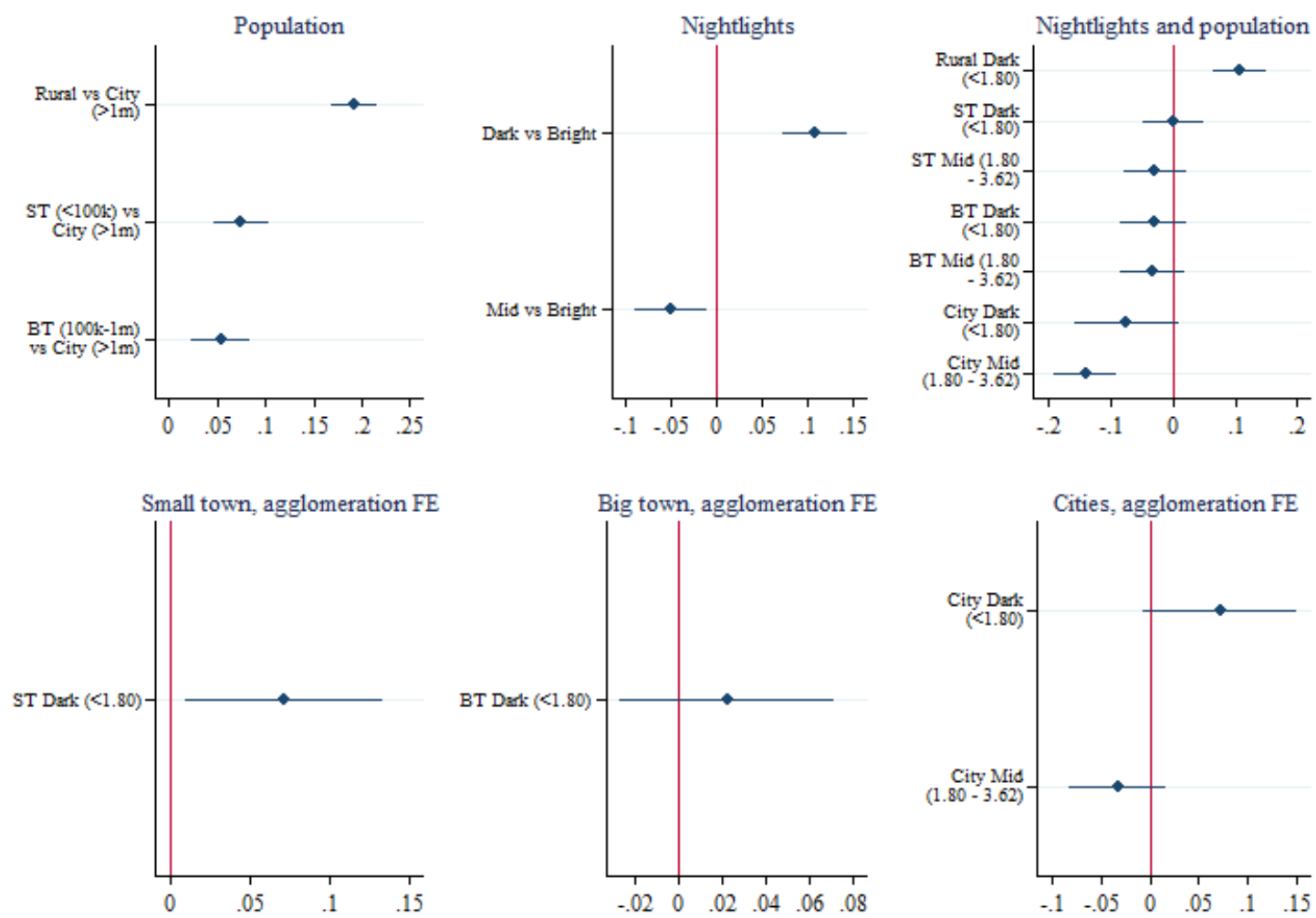

Source: 2015 DHS data for Burundi, Kenya, Ethiopia, Malawi, Mozambique, Rwanda, Tanzania, Uganda, Zambia and Zimbabwe.

Note: Coefficients and 95\% confidence intervals of probability child not stunted regressed on population and nightlight category dummies. 'City $(>1 \mathrm{~m})$ ' is the omitted category in panel 1. 'City bright $(>3.62)$ ' is the omitted category in panel 2. 'Bright ( $>3.62)$ ' is the omitted category in panel 3. ST is small towns. BT is big towns. 'Small towns mid (1.80 - 3.62) is omitted in panel 4, 'Big towns mid $(1.80-3.62)$ is omitted in panel 5 and 'City bright $(>3.62)$ ' is omitted in panel 5. Panel 4, 5 and 6 includes agglomeration fixed effects. $N=40,324$

In order to ascertain whether these effects hold within urban regions as well as across urban regions, we run agglomeration fixed effects regressions of child stunting on the population and nightlight categories for each type of urban region. Medium lit areas are omitted in panel 4 and 5 and bright areas are omitted in panel 6. Panel 4, Figure 4, shows that dark regions in small towns have higher levels of child stunting than medium lit areas within the same small town. However, dark areas within big towns do not significantly differ from medium lit areas within those same big towns (panel 5), and dark or medium lit areas within cities do not significantly differ from 
bright areas within those same cities (panel 6). We therefore cannot confirm that differences hold within these big towns and cities.

\subsection{Urban heterogeneity - Disparities between countries}

The region-wide evolution of child stunting with nighttime lights in East Africa may hide some disparities between countries. Therefore, Figure 5 presents country specific polynomial associations. These clearly indicate that the relationship between stunting and urbanization is far from uniform across East Africa.

Before we discuss this diversity, one consistent pattern for all countries is the rapid improvement in stunting across the darker regions on the left-hand side of the graphs. Children living in areas with nighttime lights under 1.80 have the highest stunting rates. This category contains $99 \%$ of all rural observations, but also some dark urban locations (see Table 1 and 2). Table A1 further explores this relationship by regressing a dummy for nighttime lights below 1.80 and above 1.80 on the probability a child is stunted (Panel A). Table A1, panel A confirms the findings from Figure 3 and 5, that children are less likely to be stunted when nighttime lights are higher than 1.80 .

After the initial decrease in stunting there are three main patterns to be discerned (Figure 5). First, in Burundi and Zimbabwe nightlight values do not reach the highest levels. Here, child stunting levels simply decrease with urbanization. Ethiopia follows the same pattern, although reaching higher levels of nighttime lights. Second, in Kenya and Zambia stunting levels-off and then increases again, following the U-shape identified in Figure 3. Third, and the most common trajectory, is that child stunting levels stagnate after a certain nighttime light value. This pattern holds for Malawi, Mozambique, Rwanda, Tanzania and Uganda. 
Figure 5 | Probability a child is stunted, per country
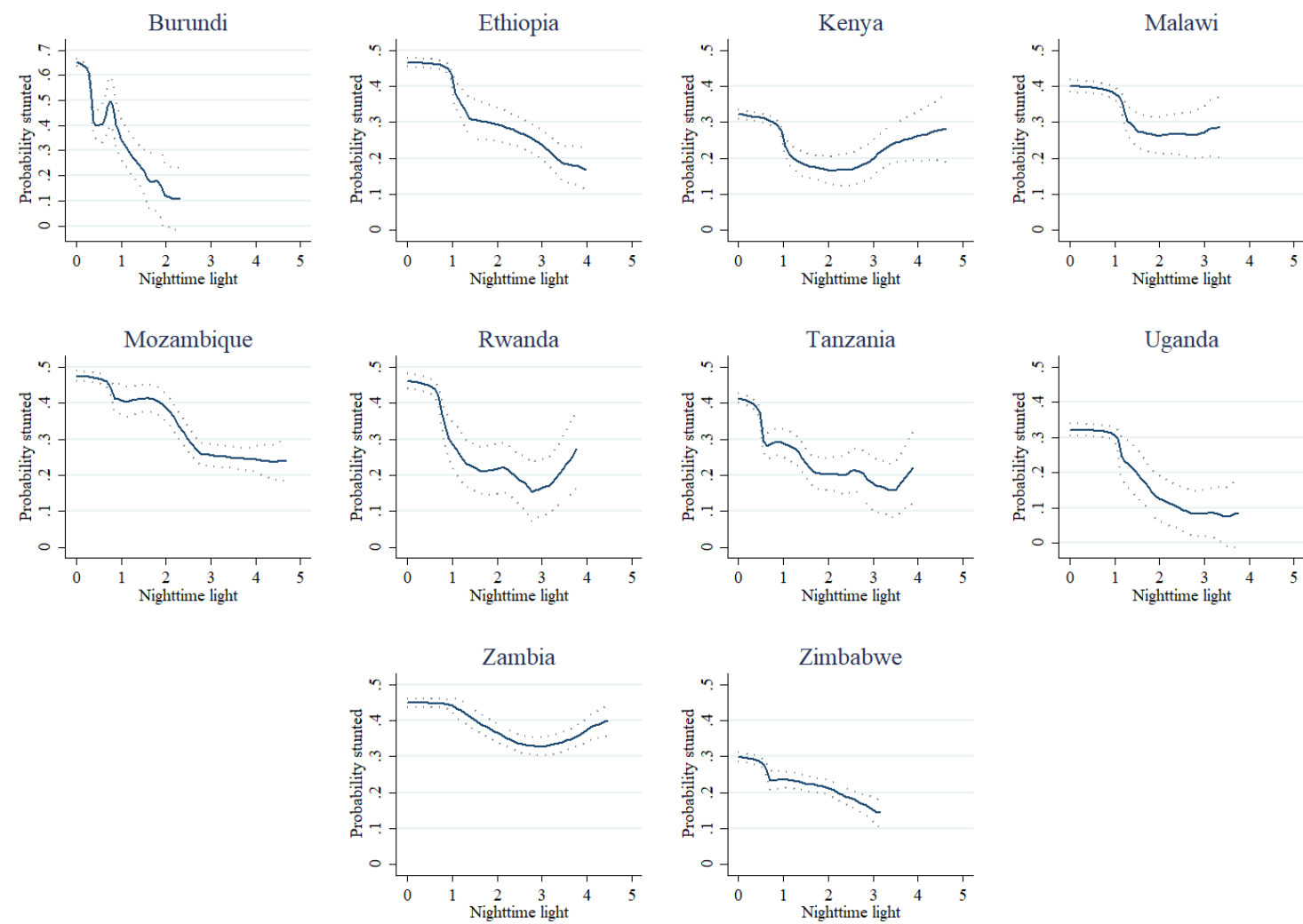

Source: 2015 DHS data for Burundi, Kenya, Ethiopia, Malawi, Mozambique, Rwanda, Tanzania, Uganda, Zambia and Zimbabwe.

Note: The nonparametric regressions are estimated through an Epanechnikov kernel function using a rule-of-thumb bandwidth estimator. The dotted lines around the plot represent the $90 \%$ confidence interval. The y-axes do not start at zero for better rendition of the graph. $N=40,324$

Table A1, panel B presents the regression results for these patterns. Here, we split the medium light category into three subgroups ${ }^{12}$ to capture the maximum nighttime lights for all countries individually. As observed from Figure 5, the range of nighttime lights varies greatly across countries. It is thus important to identify the omitted i.e. highest nightlight category properly. Burundi, for example, is a relatively dark country, with the highest nighttime lights ranging between 1.80 and 2.40. From Table A1 panel B, we can determine whether nighttime light categories lower than the brightest category have a significantly positive or negative relationship. Kenya and Zambia have a significantly lower probability of stunted children at a lower nighttime light category than the most luminous one. Countries like Burundi and Zimbabwe have a linear

\footnotetext{
${ }^{12}$ The subgroups are calculated by dividing the nighttime lights between 1.80 and 3.62 into three equal sections. Splitting the medium light category gives us a clearer overview of the range of nighttime lights per country.
} 
relationship between stunting and nighttime lights, and countries including Ethiopia, Malawi, Mozambique, Rwanda, Tanzania and Uganda have an at first decreasing relationship between stunting and nightlights, which then becomes insignificant. For these countries stunting improves as nighttime lights increase, and then levels off, with less differences between urban regions themselves.

\subsection{Wealth heterogeneity}

Average child stunting levels across the urban spectrum may also disguise how this relationship evolves at different wealth levels. It is therefore useful to look at the evolution of child stunting with urbanization for several wealth categories (Figure 6). Here we divide our wealth index into quartiles. The poorest and poor-mid $25 \%$ of households are mostly found in rural or dark areas. This explains the wide confidence intervals towards the right-hand side of panel 1 and 2 of Figure 6. On average, children from these households experience the highest levels of stunting, at about $45 \%$.

Children from mid-rich households are slightly less likely to be stunted than children from poorer wealth categories, however average levels are still around $40 \%$. For this wealth category, we find that stunting levels decrease but then rise again to an average of $50 \%$ at the highest levels of nighttime lights. Child stunting levels for the richest $25 \%$ of our sample experience a similar evolution to the mid-rich wealth category, although average stunting rates are lower. Children in the richest wealth category have, on average, a $25 \%$ probability of being stunted in dark areas, $22 \%$ probability in medium lit areas and $29 \%$ probability in bright areas. We find that it is mainly children coming from mid-rich and rich households that are driving the upturn in child stunting found in Figure 3. 
Figure 6 | Probability a child is stunted, per wealth category
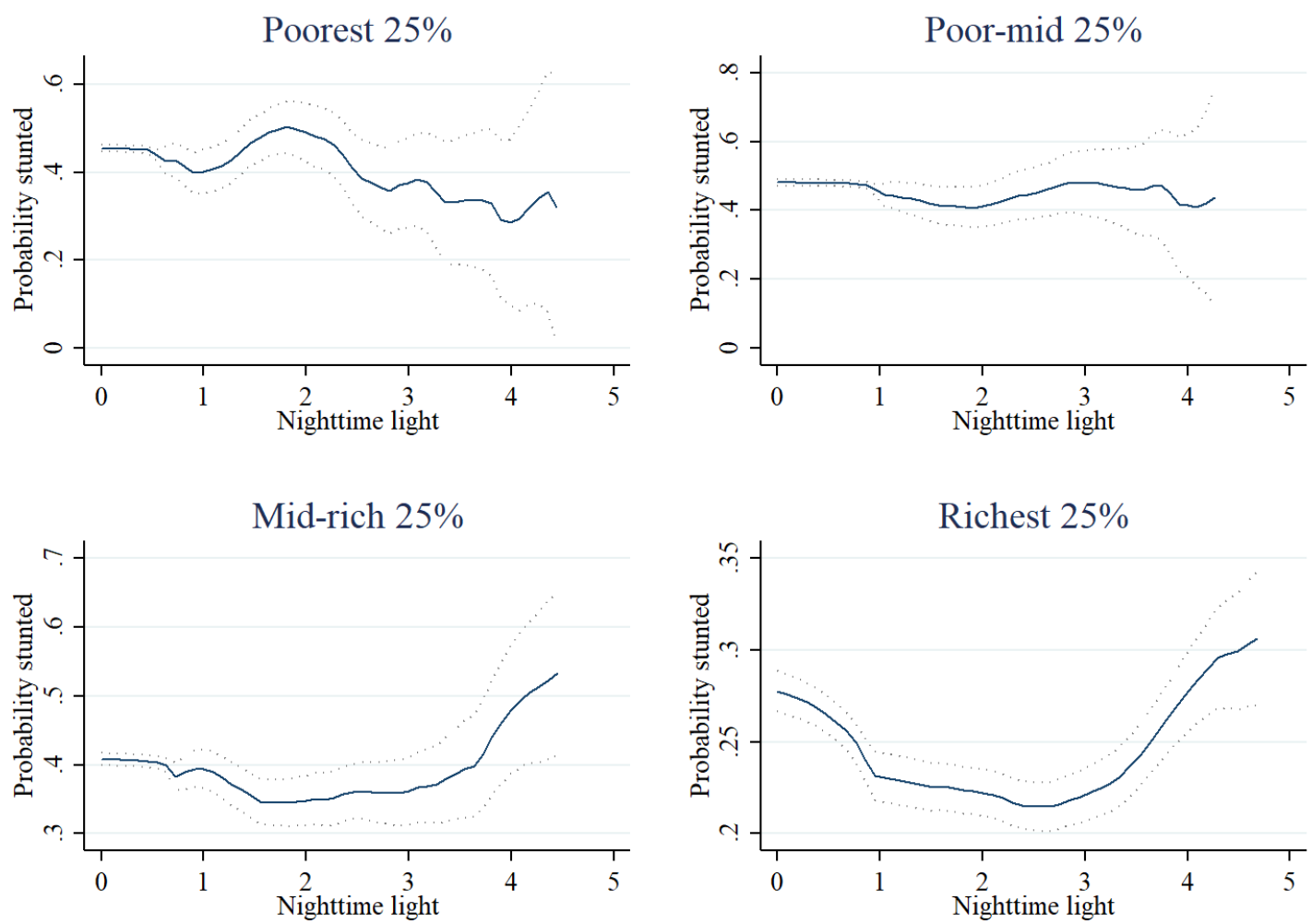

Source: 2015 DHS data for Burundi, Kenya, Ethiopia, Malawi, Mozambique, Rwanda, Tanzania, Uganda, Zambia and Zimbabwe.

Note: The nonparametric regressions are estimated through an Epanechnikov kernel function using a rule-of-thumb bandwidth estimator. The dotted lines around the plot represent the $90 \%$ confidence interval. The y-axes do not start at zero for better rendition of the graph. $N=40,324$

\section{PATHWAYS}

Thus far, the analysis has shown that child health first improves with urbanisation, but then worsens at the highest levels, in the largest cities. The data show that the improvement across the lower levels of urbanisation is true for all ten countries considered, but that the increasing levels of child stunting at the highest urbanisation levels are mainly driven by Zambia and Kenya. The effects are primarily visible for children from the two richest quartiles.

Our analysis continues with a two-pronged approach. First, in Figure 7, we plot urbanization levels against some of the known determinants of child health for which we have data. This includes data on healthcare access and sanitation, feeding practices, maternal characteristics and wealth, as explained in Section 2. We are looking for variables that follow the same trend of initial improvements and then worsening. Even if these variables may not be root causes, their role in 
determining child health has been well-established in the medical literature and we can therefore be confident that they play an important role within the causal chain. In this way, we can uncover some plausible channels through which urbanization is affecting child health.

Second, in Table 3, we run several linear probability regressions that assess the effect of nighttime lights on the probability that a child is stunted. In Panel A, we measure child stunting through the dummy Stunted ${ }_{i c}$, which takes the value 1 when child $i$, in cluster $c$ is stunted and 0 otherwise. $\operatorname{Dark}_{c}$ represents whether cluster $c$ has a nighttime light below 1.80, the left most region in Figure 3. The regressions are first run without any controls. We then add a set of basic control variables represented by the vector $X_{i c}$ containing household size, the age of the mother, whether the household head is male and a full set of dummies to control for the child's gender, age (in months) and country. To this second specification we then add vectors for healthcare access and sanitation, $H_{i c}$ (4 dummies indicating the household has a proper toilet, clean water, disposes of child waste properly and has access to a health facility), feeding practices, $F_{c}$ (cluster level averages for diet diversity score, iron-rich food consumption, minimal meal frequency and continued breastfeeding), maternal characteristics $M_{i c}$ (years of education of the mother and a dummy indicating she is earning cash income) and a constructed wealth index, $W_{i c}$. Details on the included variables can be found in Section 2. The final regression includes all variables simultaneously, as follows:

$$
\text { Stunted }_{i c}=\beta \text { Dark }_{c}+\delta X_{i c}+\theta_{1} H_{i c}+\theta_{2} F_{c}+\theta_{3} M_{i c}+\theta_{4} W_{i c}+e_{i c}
$$

where $e_{i c}$ is the error term.

The first column in Table 3, panel A, repeats the result from the previous section showing that $\beta>0$. The second column shows that adding the basic control variables $\left(X_{i c}\right)$ reduces the coefficient slightly from around 16.1 to 14.7 percentage points, but the difference between dark and medium to bright areas remains large and very significant. Section 4.1. to 4.4. will discuss how the size and significance of $\beta$ varies when adding other controls to inform on whether these are likely pathways through which the initial improvement in child stunting happens. 
Table 3, panel B, presents a similar set-up in which we investigate plausible pathways explaining the increase in child stunting on the right-hand side of Figure 3. We split the nightlight data up into three dummies, representing the three areas identified in Figure 3: dark areas with nightlights lower than $1.80\left(\right.$ Dark $\left._{c}\right)$, medium areas with nightlights between 1.80 and $3.62\left(\right.$ Medium $\left._{c}\right)$ and bright areas with nightlights above 3.62. Using the latter group as the omitted category, we build the regressions up in a similar way as before, with the final full regression as follows:

$$
\text { Stunted }_{i c}=\beta_{1} \text { Dark }_{c}+\beta_{2} \text { Medium }_{c}+\delta X_{i c}+\theta_{1} H_{i c}+\theta_{2} F_{c}+\theta_{3} M_{i c}+\theta_{4} W_{i c}+e_{i c}
$$

Here we are interested in $\beta_{1}$ and $\beta_{2}$. The pattern discussed regarding Figure 3 is one where $\beta_{1}>0$ and $\beta_{2}<0$. The first column in Table 3, panel B shows that stunting levels in dark areas are 8.8 percentage points above those in bright areas, while medium lit areas have stunting levels that are 9.5 percentage points lower than those in bright areas. Adding basic controls attenuates the difference between bright and medium lit areas, but not as much between bright and dark areas. In section 4.1. to 4.4. we will discuss how the coefficients change as we add the controls representing possible pathways. ${ }^{13}$

\footnotetext{
${ }^{13}$ Full regression results can be found in the appendix, Table A2 for Table 3 Panel A and Table A3 for
} Table 3 Panel B. 
Figure 7 | Urbanization and determinants of child stunting
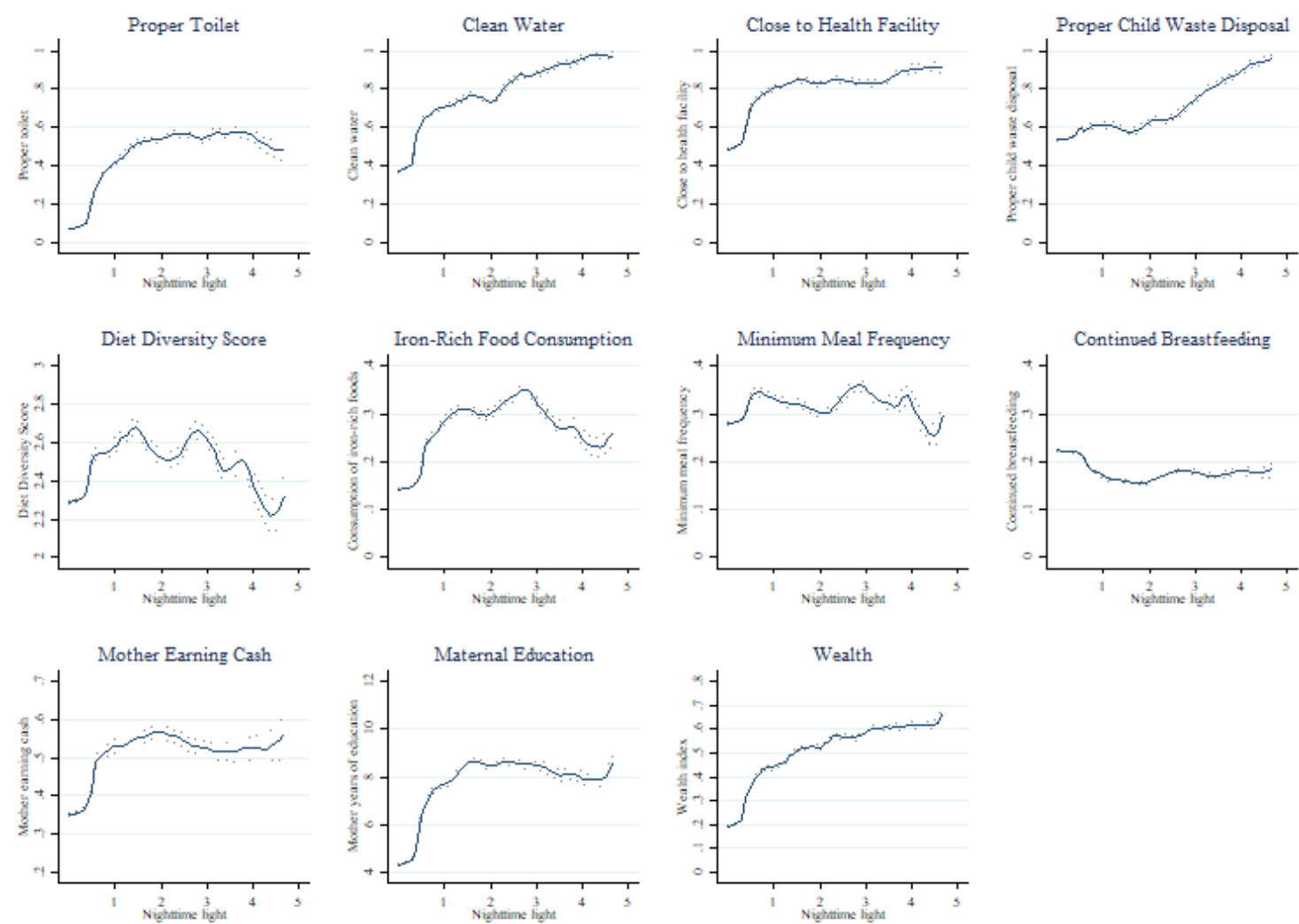

Source: 2015 DHS data for Burundi, Ethiopia, Kenya, Malawi, Mozambique, Rwanda, Tanzania, Uganda, Zambia and Zimbabwe.

Note: The nonparametric regressions are estimated through an Epanechnikov kernel function using a rule-of-thumb bandwidth estimator. The dotted lines around the plot represent the $90 \%$ confidence interval. The y-axes do not start at zero for better rendition of the graph. $N=40,324$

\subsection{Healthcare access and sanitation}

The first row of Figure 7 provides polynomial associations between nighttime lights and sanitation, clean water and access to health care. These important health inputs are found to improve with urbanization. Households are almost 50 percentage points more likely to have an improved toilet in large cities and almost $100 \%$ of all high level urban households have access to clean water and dispose of child waste properly. Health facilities are also considerably easier to reach, with only $50 \%$ of rural households stating that they have an easily accessible healthcare facility compared to $90 \%$ in cities.

When adding these sanitation and healthcare variables to the regressions for dark areas compared to the omitted group of areas with a nightlight higher than 1.80 (column 3 of Table 3, Panel A) we see a much reduced coefficient, suggesting these factors are important in explaining the initial 
improvement in child stunting. Initially, child stunting levels are between 16 and 15 percentage points higher in dark areas than in areas with a nightlight higher than 1.80 (column 1 and 2 respectively). These differences reduce by 7-8 percentage points when controlling for healthcare access and sanitation.

Panel B, provides similar results for dark vs bright regions. Table 3, panel B column 3, shows that $\beta_{1}$ reduces in size and also loses significance. However, we see very little change in size or significance with respect to the coefficients measuring the difference between the medium and bright areas, $\beta_{2}$. This suggests, in line with Figure 7, that differences in sanitation and healthcare access do not explain the increased stunting levels in the brightest urban areas but can attribute to the improvement in child stunting from dark to brighter lit areas.

\subsection{Feeding practices}

Dietary quality is also a key determinant of child health outcomes and may differ across various levels of urbanization. The DHS data allow us to establish cluster level averages for feeding practices, which we can relate to cluster level nighttime light data. Figure 7, row 2, presents four key feeding practices, namely a diet diversity score (the score ranges from 1 to 7 ), a dummy for whether the child consumed iron-rich food, a dummy for whether they attained a minimum frequency of meals and a dummy for whether there was continued breastfeeding after 12 months old. Looking at the diet diversity score portrayed in Figure 7, we find that this pattern perfectly mirrors that of child stunting (Figure 3). Furthermore, iron-rich food consumption and minimum meal frequency follow similar patterns, with better consumption rates in medium lit areas and a dip in consumption in the brightest areas. Lastly, continued breastfeeding decreases steadily as urbanization increases, although relatively low across the board. This may be associated with higher time constraints and parental opportunity costs in cities (see next section).

Further evidence supporting the nutrition channel comes from child wasting and anaemia patterns across the nighttime light spectrum (Figure A4). Both follow the same pattern as stunting, but for anaemia we can clearly distinguish the $\mathrm{U}$ shape. The confidence intervals for wasting are too wide 
to conclude the same. ${ }^{14}$ Considering these findings, children most likely access sufficient calories (as evidenced by wasting), but the problem lies with the nutritional content of the food they consume (which the anaemia levels suggest). ${ }^{15}$

From the regressions in Table 3, we find that the feeding practice environment has a small impact on the differences in child stunting between dark and light areas. In panel A, column 4, the coefficient of interest drops from 14.7 to 13.5 percentage points when controlling for cluster level feeding practices. In panel B, the coefficients of interest essentially remain unchanged. This may be due to the fact that we use a coarse cluster level measure.

\subsection{Maternal characteristics}

On the one hand maternal earnings can represent an opportunity cost for a mother's time inputs, possibly having negative effects on children. On the other hand, they could imply more femalecontrolled resources and correlate with maternal characteristics that have a positive effect on child health, such as the mother's education. In the first panel of row 3, Figure 7, we see that the share of women who earn cash increases with nighttime lights. This share reaches a peak at a nighttime light of about 2, decreases slightly, then levels off. In row 3, panel 2 of Figure 7, we see that the average years of formal education also increases with nighttime lights. This variable follows a similar pattern to maternal earnings in cash.

When controlling for maternal earnings in cash and education levels, we find a substantial drop in the coefficient sizes for the regressions in Table 3, column 5. Including maternal characteristics reduces the difference in child stunting between areas with a nightlight below and above 1.80 by almost 6 percentage points (Panel A). Panel B shows that when comparing dark and bright regions, child stunting differs by 4 percentage points when controlling for maternal

\footnotetext{
${ }^{14}$ It must be noted that wasting levels are generally quite low and so the lack of variability may influence this result.

${ }^{15} \mathrm{We}$ call this suggestive evidence of the nutrition channel as there are several types of anaemia, some of which can also be due to non-nutrition related factors such as intestinal worms or internal blood loss. Intestinal worms are however more common in rural areas, so the fact that anaemia decreases at the highest levels of urbanization is most likely related to undernutrition than other causes. The anaemia spectrum starts at 1 , which indicates severe anaemia, up to 4 which specifies no anaemia.
} 
characteristics, compared to 9 percentage points without these controls (column 2), as well as a drop in significance. The coefficient illustrating the increase in child stunting levels between medium and brightly lit areas, however, remains the same.

\subsection{Wealth}

Differences in health inputs such as sanitation, healthcare access, feeding practices and maternal characteristics undoubtedly play a role in explaining why we see such large differences across the urban spectrum. Yet, these in themselves may be driven by deeper rooted determinants, which also vary by level of urbanization, such as differences in wealth. Controlling for wealth is important as the literature commonly finds that stunting, as well as other nutritional outcomes, improve with wealth (Sahn, 1994; Christiaensen \& Alderman, 2004), which also strongly increases with urbanization. This is also evident in our sample, shown by the positive relationship between household wealth and nighttime lights, row 3, panel 3 of Figure 7. Wealth differentials can also play a greater role in urban areas, due to larger disparities within the region (Menon et al., 2000). Asset poverty is expected to be especially important from the age of 24 months and older (Fotso et al., 2012).

Including the wealth index in the regressions has a significant impact on the coefficients. From panel A, we can see that adding wealth, completely explains away the difference in child stunting between dark and medium-bright lit areas (column 6). Compared to a child stunting difference of 15 percentage points in column 2, this drops to a 1 percentage point difference in column 6 and loses significance. When adding the wealth index into the regressions comparing the three levels of nighttime lights, we find that the coefficient for dark vs bright areas changes from a positive to a negative sign. The coefficient for medium vs bright areas increases and remains strongly significant. Once we consider wealth differences it becomes even harder to explain why stunting goes up in brighter areas. These findings align with our observations from Figure 5, showing that children from mid-rich and rich households mainly experience an increase in stunting levels at the highest levels of urbanization. 
The final column in Table 3 adds all the variables to the model. This gives an insignificant urbanrural difference, but very little changes for the coefficient measuring the difference between medium-lit and bright regions. Nevertheless, it must be noted that even after adding all variables, our model can only explain $9 \%$ of the observed variation in child stunting rates of the sample. 
Table 3 | Regression results for child stunting and nighttime lights

$$
\text { (1) (2) }
$$

VARIABLES Nighttime lights

Controls

Health Inputs

Feeding practices

Maternal characteristics

Wealth

All variables

\section{Panel A:}

Dark $(0$ - 1.80) vs NL > 1.80

$0.161 * * *$

$0.147 * * *$

$0.0797 * * *$

$0.135 * * *$

$0.0902 * * *$

0.0113

0.00164

(0.00896)

$(0.0101)$

(0.00904)

(0.00929)

(0.0107)

(0.0108)

\begin{tabular}{|c|c|c|c|c|c|c|c|}
\hline Observations & 40,324 & 40,324 & 40,324 & 40,324 & 40,324 & 40,324 & 40,324 \\
\hline R-squared & 0.011 & 0.064 & 0.070 & 0.065 & 0.078 & 0.079 & 0.086 \\
\hline \multicolumn{8}{|l|}{ Panel B: } \\
\hline Dark $(0-1.80)$ vs Bright $(>3.62)$ & $\begin{array}{c}0.0876 * * * \\
(0.0214)\end{array}$ & $\begin{array}{c}0.0931 * * * \\
(0.0212)\end{array}$ & $\begin{array}{c}0.0214 \\
(0.0219)\end{array}$ & $\begin{array}{c}0.0848 * * * \\
(0.0214)\end{array}$ & $\begin{array}{l}0.0378 * \\
(0.0212)\end{array}$ & $\begin{array}{c}-0.0634 * * * \\
(0.0223)\end{array}$ & $\begin{array}{c}-0.0684 * * * \\
(0.0223)\end{array}$ \\
\hline Medium (1.80 - 3.62) vs Bright (> 3.62) & $\begin{array}{c}-0.0945^{* * * *} \\
(0.0230)\end{array}$ & $\begin{array}{c}-0.0687 * * * \\
(0.0227)\end{array}$ & $\begin{array}{c}-0.0738 * * * \\
(0.0228)\end{array}$ & $\begin{array}{c}-0.0636 * * * \\
(0.0228)\end{array}$ & $\begin{array}{c}-0.0667 * * * \\
(0.0224)\end{array}$ & $\begin{array}{c}-0.0929 * * * \\
(0.0226)\end{array}$ & $\begin{array}{c}-0.0873 * * * * \\
(0.0225)\end{array}$ \\
\hline Observations & 40,324 & 40,324 & 40,324 & 40,324 & 40,324 & 40,324 & 40,324 \\
\hline R-squared & 0.012 & 0.064 & 0.071 & 0.066 & 0.078 & 0.080 & 0.087 \\
\hline \multicolumn{8}{|l|}{ Controls } \\
\hline Basic controls & & $\mathrm{x}$ & $\mathrm{x}$ & $\mathrm{x}$ & $\mathrm{x}$ & $\mathrm{x}$ & $\mathrm{x}$ \\
\hline Health inputs & & & $\mathrm{x}$ & & & & $\mathrm{x}$ \\
\hline Feeding practices & & & & $\mathrm{x}$ & & & $\mathrm{x}$ \\
\hline Maternal characteristics & & & & & $\mathrm{x}$ & & $\mathrm{x}$ \\
\hline Wealth & & & & & & $\mathrm{x}$ & $\mathrm{x}$ \\
\hline
\end{tabular}

Robust standard errors in parentheses

$* * * \mathrm{p}<0.01, * * \mathrm{p}<0.05, * \mathrm{p}<0.1$

Note: Linear probability model explaining child stunting and urbanization. Basic controls include mother's age, whether household head is male, household size and a full set of dummies for gender, age (in months) and country. Healthcare access and sanitation includes four dummies on whether the household has an accessible health facility, a proper toilet (defined by having a flushing system or ventilated improved latrine), clean water (defined by piped into the dwelling or plot, coming from a public tap or tube well, a tanker truck or bottled water), disposes of child waste properly (defined by flushing waste down a toilet or latrine or thrown into the garbage). Feeding practices are based on cluster levels averages. They include a diet diversity score (1-7), iron-rich food consumption, minimum meal frequency and continued breastfeeding after 12 months of age. Maternal characteristics include a dummy on mother earning in cash and years of formal education of the mother. Wealth is represented by a wealth index calculated by a multiple correspondence analysis using household assets (electricity, radio, television, refrigerator, bicycle, motorcycle, car/truck, tile/concrete floor, metal roof, cement walls and non-wood cooking fuel). 


\section{PATHWAY HETEROGENEITY}

The U-shaped pattern of child stunting with urbanization was found to be driven by two countries and by the two highest wealth quartiles. It is therefore worth repeating the previous analysis specifically for subgroups of the sample defined along these lines.

\subsection{Country disparities}

As identified in Section 3.3, there are significant differences in child stunting outcomes and urbanization between countries. Therefore, we repeat our analysis from Figure 7 and Table 3 for two separate groupings of countries: Kenya and Zambia, and the rest (Burundi, Ethiopia, Malawi, Mozambique, Rwanda, Tanzania, Uganda and Zimbabwe).

First, Figure A5 and A6 mimic the structure presented in Figure 7. When solely analysing these patterns for Kenya and Zambia (Figure A5), we find that certain health inputs do not follow the continuous upward trend that was observed in Figure 7. Whether a household has an improved toilet decreases at the highest nighttime lights, and access to water stagnates after a certain level of urbanization. In general, feeding practices do not differ greatly between Kenya and Zambia and other countries, although minimum meal frequency is lower. Most noteworthy is that maternal education levels fall at the highest levels of nighttime lights and whether the mother earns cash is lower for these countries than for the others. Lastly, wealth levels are lower across the board and also increase at a slower pace with urbanization in Kenya and Zambia than for other countries. It may be that in Kenya and Zambia, the combination of lower maternal earnings in cash and lower educational levels, with a slower improvement in healthcare access, sanitation and wealth lead to worse health outcomes for children.

When reassessing the regression results for the split subsamples of countries, we find similar results. First, the main regression result from Table 3 panel B, column 1 and 2, does not hold when looking at countries excluding Kenya and Zambia (Table A4, panel B). When adding the basic controls, these countries experience improvements in child stunting levels as nighttime lights increase, confirming that children in Kenya and Zambia are driving the U-shaped results. 
Table A5 presents the regression results for Kenya and Zambia. As previously found, healthcare access and sanitation, feeding practices, maternal characteristics and wealth come out as pathways through which stunting levels decrease at lower levels of urbanisation, but not for the increase at higher levels. ${ }^{16}$

\subsection{Wealth disparities}

As observed in section 3.4. and from Table 3, wealth has a profound influence on child stunting levels across the rural-urban spectrum. The patterns from Figure 7 are confirmed by regressions following the structure used in Table 3 panel B, but run for the separate wealth categories (Table A6). The results confirm that the increase in child stunting levels with urbanization are captured by the mid-rich $25 \%$ and the richest $25 \%$ of households. Children from the poorest $25 \%$ or poormid $25 \%$ show no significant difference in stunting levels across the three nighttime light categories. Children from mid-rich households, living in bright urban areas, are about 13 percentage points more likely to be stunted compared to those living in medium lit areas (Table A6, panel C). There is no significant difference between bright and dark area stunting levels. These patterns hold for the richest households, although the difference is reduced to about 8 percentage points. For the mid-rich households we find that maternal characteristics explain some of the differences in child stunting between medium lit and bright regions (Table A6, column 5, panel C). Coefficient $\beta_{2}$ drops by 2.6 percentage points and becomes insignificant, but the standard error changes very little.

Overall, the U-shaped pattern identified in Figure 3, and especially the increase in child stunting at the highest levels of nighttime lights, is driven by child stunting differences between medium and bright lit areas for the mid-rich and richest households. There is some suggestive evidence that this is related to maternal characteristics.

\footnotetext{
${ }^{16}$ Data limitations restrict the identification of drivers behind the upturn in child stunting in bright urban regions. Further data on food prices, supermarket availability and quality, child care alternatives and individual child feeding practices are needed.
} 


\section{CONCLUSION}

In East Africa child stunting is highest in rural areas, followed by small and big towns and is, on average, lowest in cities. We use nighttime lights data to look behind these agglomeration-level averages and find that child stunting first improves with nighttime lights but then deteriorates at the highest levels. This region-wide pattern hides important differences across countries. While in all ten countries child stunting decreases quickly at the lower levels of brightness, for some countries this trend continues linearly, for others it tapers off, and for some there is an increase at the highest levels of nighttime lights. It is mainly in bright areas of large cities that child stunting levels worsen again. Child growth is often best in medium-lit areas of big towns and cities. The increase in child stunting at the highest levels of urbanisation is primarily driven by children from families with above-median wealth.

We seem to have a good understanding of why dark areas fare so much worse than medium lit and bright areas. Sanitation, water, healthcare access, maternal characteristics and wealth play a crucial role here. The most promising explanation for the increased stunting levels in the brightest areas compared to the medium lit areas comes from the feeding practices data. Diet diversity, minimum meal frequency, continued breastfeeding and iron-rich food consumption all go down in the brightest areas. Even for countries where child stunting tapers off at the highest levels of nighttime lights, these feeding practices all decrease. This finding is strengthened by the fact that anaemia also increases in these areas. For policy makers this would suggest that targeted interventions on feeding practices can have high pay-offs in both rural and highly urbanised regions.

At the same time we are careful not to overstate that these are core drivers of the observed pattern, as controlling for feeding practices in a regression framework does not eliminate the measured gap. That said, feeding practices and parental characteristics seem like a very good place to start for future research on mediating factors. Our analysis only includes crude data on maternal earnings and cluster level data for feeding practices. Future research with better earnings and time use data could investigate the changing role of female employment, time allocation and changes 
in female-earned income across the urban spectrum and how this interacts with child health through pathways such as feeding practices. 


\section{REFERENCES}

Ahmed, F. (2000). Anaemia in Bangladesh: a review of prevalence and aetiology. Public Health Nutrition, 3(4), 385-393.

Amare, M., Arndt, C, Abay, K. A., Benson, T. (2018) Urbanization and Child Nutritional Outcomes. The World Bank Economic Review, lhy015.

Alderman, H., \& Headey, D. (2018). The timing of growth faltering has important implications for observational analyses of the underlying determinants of nutrition outcomes. PloS one, 13(4), e0195904.

Atkinson, S. J. (1992). Food for the cities: Urban nutrition policy in developing countries.

Barrett, C. B., Christiaensen, L., Sheahan, M., \& Shimeles, A. (2017). On the structural transformation of rural Africa. Journal of African Economies, 26(suppl_1), i11-i35.

Berdegue, J., Proctor, F., and Cazzu, C. (2014). Inclusive rural-urban linkages. Working Paper Series of the Latin American Center for Rural Development,123.

Berkman, D. S., Lescano, A. G., Gilman, R. H., Lopez, S. L., \& Black, M. M. (2002). Effects of stunting, diarrhoeal disease, and parasitic infection during infancy on cognition in late childhood: a follow-up study. The Lancet, 359(9306), 564-571.

Black, R. E., Allen, L. H., Bhutta, Z. A., Caulfield, L. E., De Onis, M., Ezzati, M., ... \& Maternal and Child Undernutrition Study Group. (2008). Maternal and child undernutrition: global and regional exposures and health consequences. The Lancet, 371(9608), 243-260.

Bobonis, G. J., Miguel, E., \& Puri-Sharma, C. (2006). Anemia and school participation. Journal of Human resources, 41(4), 692-721.

Booysen, F., Van Der Berg, S., Burger, R., Von Maltitz, M., \& Du Rand, G. (2008). Using an asset index to assess trends in poverty in seven Sub-Saharan African countries. World Development, 36(6), 1113-1130. 
Burchfield, M., Overman, H. G., Puga, D., \& Turner, M. A. (2006). Causes of sprawl: A portrait from space. The Quarterly Journal of Economics, 121(2), 587-633.

Caulfield, L. E., Richard, S. A., Rivera, J. A., Musgrove, P., \& Black, R. E. (2006). Stunting, wasting, and micronutrient deficiency disorders.

Celnik, D., Gillespie, L., \& Lean, M. E. J. (2012). Time-scarcity, ready-meals, ill-health and the obesity epidemic. Trends in food science \& technology, 27(1), 4-11.

Christiaensen, L., \& Alderman, H. (2004). Child malnutrition in Ethiopia: can maternal knowledge augment the role of income? Economic Development and cultural change, 52(2), 287312.

Christiaensen, L., De Weerdt, J., \& Todo, Y., (2013). Urbanization and poverty reduction: the role of rural diversification and secondary towns. Agricultural Economics, 44(4-5):435-447.

Christiaensen, L., De Weerdt J., \& Kanbur, R. (2017). Where to create jobs to reduce poverty: cities or towns? A theory of Migration Equilibrium and Income Distribution. World Bank Policy Research Working Paper 8069 Mimeo.

Christiaensen, L., De Weerdt J., \& Kanbur, R. (2019). Decomposing the contribution of migration to poverty reduction: methodology and application to Tanzania. Applied Economics Letters 26(12):978-982.

Christiaensen, L., \& Todo, Y. (2014). Poverty reduction during the rural-urban transformationthe role of the missing middle. World Development, 63, 43-58.

Choudhury, S., Headey, D. D., \& Masters, W. A. (2019). First foods: Diet quality among infants aged 6-23 months in 42 countries. Food Policy, 88, 101762.

Cockx, L, Colen, L., \& De Weerdt, J. (2018). From Corn to Popcorn? Urbanization and food consumption in sub-Sahara Africa: Evidence from rural-urban migrants in Tanzania. World Development 110:140-159. 
Crush, J., Frayne, B., \& McLachlan, M. (2011). Rapid urbanization and the nutrition transition in Southern Africa. African Food Security Urban Network (AFSUN).

Doak, C. M., Adair, L. S., Bentley, M., Monteiro, C., Popkin, B. M. (2005). The dual burden household and the nutrition transition paradox. International Journal of Obesity, 29(1), 129-36.

Donaldson, D., \& Storeygard, A. (2016). The view from above: Applications of satellite data in economics. Journal of Economic Perspectives, 30(4), 171-98.

Dorosh, P., \& Thurlow, J. (2013). Agriculture and small towns in Africa. Agricultural Economics, 44(4-5), 449-459.

Elvidge, C. D., Baugh, K. E., Zhizhin, M., \& Hsu, F. C. (2013). Why VIIRS data are superior to DMSP for mapping nighttime lights. Proceedings of the Asia-Pacific Advanced Network, 35(0), 62.

Ezzrari, A., \& Verme, P. (2012). A multiple correspondence analysis approach to the measurement of multidimensional poverty in Morocco, 2001-2007. The World Bank.

Firestone, R., Punpuing, S., Peterson, K. E., Acevedo-Garcia, D., \& Gortmaker, S. L. (2011). Child overweight and undernutrition in Thailand: Is there an urban effect?. Social science \& medicine, 72(9), 1420-1428.

Fotso, J. C. (2007). Urban-rural differentials in child malnutrition: trends and socioeconomic correlates in sub-Saharan Africa. Health \& Place, 13(1), 205-223.

Fotso, J. C., Madise, N., Baschieri, A., Cleland, J., Zulu, E., Mutua, M. K., \& Essendi, H. (2012). Child growth in urban deprived settings: does household poverty status matter? At which stage of child development?. Health \& place, 18(2), 375-384.

Glasser, M., \& Raich, U. (2008). The urban transition in Tanzania. World Bank, Washington, DC.

Glewwe, P., Jacoby, H. G., \& King, E. M. (2001). Early childhood nutrition and academic achievement: a longitudinal analysis. Journal of Public Economics, 81(3), 345-368. 
Grantham-McGregor, S. M., Walker, S. P., \& Chang, S. (2000). Nutritional deficiencies and later behavioural development. Proceedings of the Nutrition society, 59(01), 47-54.

Halterman, J. S., Kaczorowski, J. M., Aligne, C. A., Auinger, P., \& Szilagyi, P. G. (2001). Iron deficiency and cognitive achievement among school-aged children and adolescents in the United States. Pediatrics, 107(6), 1381-1386.

Hawkes, C. (2008). Dietary implications of supermarket development: a global perspective. Development Policy Review 26(6), 657-692.

Headey, D., Stifel, D., You, L., \& Guo, Z. (2018). Remoteness, urbanization, and child nutrition in sub-Saharan Africa. Agricultural Economics, 49(6), 765-775.

Henderson, V. (2002). Urbanization in developing countries. The World Bank Research Observer, 17(1), 89-112.

Henderson, J. V., Storeygard, A., \& Weil, D. N. (2012). Measuring economic growth from outer space. American economic reviSotoew, 102(2), 994-1028.

Henderson, M., Yeh, E. T., Gong, P., Elvidge, C., \& Baugh, K. (2003). Validation of urban boundaries derived from global night-time satellite imagery. International Journal of Remote Sensing, 24(3), 595-609.

Hirvonen, K. (2016). Rural-urban differences in children's dietary diversity in Ethiopia: A poisson decomposition analysis. Economics Letters 147(2016):12-15.

Ingelaere, B., Christiaensen, L., De Weerdt, J., \& Kanbur, R. (2018). Why Secondary Towns Can Be Important for Poverty Reduction: A Migrant's Perspective. World Development 105:273-282.

Kanbur, R., Christiaensen L. \& De Weerdt, J. (2019). Where to create jobs to reduce poverty: cities or towns? Journal of Economic Inequality (forthcoming).

Kulwa, K. B., Kinabo, J. L., \& Modest, B. (2006). Constraints on good child-care practices and nutritional status in urban Dar-es-Salaam, Tanzania. Food and Nutrition Bulletin, 27(3), 236-244. 
Lozoff, B., Jimenez, E., Hagen, J., Mollen, E., \& Wolf, A. W. (2000). Poorer behavioral and developmental outcome more than 10 years after treatment for iron deficiency in infancy. Pediatrics, 105(4), e51-e51.

Lu, D., Tian, H., Zhou, G., \& Ge, H. (2008). Regional mapping of human settlements in southeastern China with multisensor remotely sensed data. Remote Sensing of Environment, 112(9), 3668-3679.

Luo, R., Shi, Y., Zhang, L., Liu, C., Rozelle, S., Sharbono, B., ... \& Martorell, R. (2012). Nutrition and educational performance in rural China's elementary schools: Results of a randomized control trial in Shaanxi Province. Economic development and cultural change, 60(4), 735-772.

Marmot, M. (2006). Health in an unequal world: social circumstances, biology and disease. Clinical Medicine, 6(6), 559.

Mellor, J. W. (2017). Cities, Consumption, and Marketing Dynamics. Agricultural Development and Economic Transformation (pp. 195-205). Palgrave Macmillan, Cham.

Menon, P., Ruel, M. T., \& Morris, S. S. (2000). Socio-economic differentials in child stunting are consistently larger in urban than in rural areas. Food and Nutrition Bulletin, 21(3), 282-289.

Montgomery, M. R., Stren, R., Cohen, B., \& Reed, H. E. (2013). Cities transformed: demographic change and its implications in the developing world. Routledge.

Peeling, A. N., \& Smart, J. L. (1994). Review of literature showing that undernutrition affects the growth rate of all processes in the brain to the same extent. Metabolic brain disease, 9(1), 33-42.

Pollitt, E. (1995). Does breakfast make a difference in school? Journal of the American Dietetic Association, 95(10), 1134-1139.

Popkin, B. M. (1999). Urbanization, lifestyle changes and the nutrition transition. World Development 27(11), 1905-1916. http://dx.doi.org/10.1016/S0305-750X(99)00094-7

Popkin, B. M. (2001). The nutrition transition and obesity in the developing world. The Journal of nutrition, 131(3), 871S-873S. https://doi.org/10.1093/jn/131.3.871S 
Ravallion, M. (2017). A concave log-like transformation allowing non-positive values. Economics Letters, 161, 130-132.

Ronald, L. A., Kenny, S. L., Klinkenberg, E., Akoto, A. O., Boakye, I., Barnish, G., \& Donnelly, M. J. (2006). Malaria and anaemia among children in two communities of Kumasi, Ghana: a cross-sectional survey. Malaria Journal, 5(1), 105.

Ruel, M. T., Garrett, J. L., Morris, S. S., Maxwell, D., Oshaug, A., Engle, P., ... \& Haddad, L. (1998). Urban challenges to food and nutrition security: a review of food security, health, and caregiving in the cities. Washington, DC: IFPRI.

Ruel, M. T., Garrett, J. L., \& Haddad, L. (2008). Rapid urbanization and the challenges of obtaining food and nutrition security. Nutrition and health in developing countries (pp. 639-656). Humana Press.

Sahn, D. E. (1994). The contribution of income to improved nutrition in Côte d'Ivoire. Journal of African Economies, 3(1), 29-61.

Sastry, N. (1997). What explains rural-urban differentials in child mortality in Brazil?. Social science \& medicine, 44(7), 989-1002.

Shorr, A. F., Doyle, J., Stern, L., Dolgitser, M., \& Zilberberg, M. D. (2008). Anemia in chronic obstructive pulmonary disease: epidemiology and economic implications. Current medical research and opinion, 24(4), 1123-1130.

Smith, J. P. (1999). Healthy bodies and thick wallets: the dual relation between health and economic status. Journal of Economic perspectives, 13(2), 145-166.

Smith, L. C., Ruel, M. T., \& Ndiaye, A. (2005). Why is child malnutrition lower in urban than in rural areas? Evidence from 36 developing countries. World Development, 33(8), 1285-1305.

Sutton, P. C., Elvidge, C., \& Obremski, T. (2003). Building and evaluating models to estimate ambient population density. Photogrammetric Engineering \& Remote Sensing, 69(5), 545-553. 
Sutton, P.C., Taylor, M.J., \& Elvidge, C.D. (2010). Using DMSP OLS Imagery to Characterize Urban Populations in Developed and Developing Countries. In Remote Sensing of Urban and Suburban Areas, edited by T. Rashed and C. Jü, 329-348. Berlin: Springer

Tinker, I. (1997). Street foods: Urban food and employment in developing countries. Oxford University Press.

Traissac, P., \& Martin-Prevel, Y. (2012). Alternatives to principal components analysis to derive asset-based indices to measure socio-economic position in low-and middle-income countries: the case for multiple correspondence analysis. International journal of epidemiology, 41(4), 1207 1208.

UNCHS. United Nations Centre for Human Settlements. (2001). The State of the World's Cities, 2001 (Vol. 27). UN-HABITAT.

UN Habitat (2014). The State of the African Cities 2014 - Reimagining Sustainable Urban Transitions. UN Habitat Report.

UNICEF. (2018). UNICEF data: monitoring the situation of children and women. New York.

Van de Poel, E., O’Donnell, O., \& Van Doorslaer, E. (2007). Are urban children really healthier? Evidence from 47 developing countries. Social science \& medicine, 65(10), 1986-2003.

Van de Poel, E., O'Donnell, O., \& Van Doorslaer, E. (2012). Is There a Health Penalty of China's Rapid Urbanization? Health Economics 21 (4): 367-385.

Vandercasteelen, J., Tamru, S., Minten, B., \& Swinnen, J. (2017). Secondary towns, agricultural prices, and intensification: evidence from Ethiopia (Vol. 102). Intl Food Policy Res Inst.

Von Braun, J. (1993). Urban food insecurity and malnutrition in developing countries: Trends, policies, and research implications. Intl Food Policy Res Inst.

World Health Organization. (2008). Indicators for assessing infant and young child feeding practices: part 1: definitions: conclusions of a consensus meeting held 6-8 November 2007 in Washington DC, USA. 
World Health Organization, \& World Health Organization: Nutrition for Health. (2009). WHO child growth standards: growth velocity based on weight, length and head circumference: methods and development. World Health Organization.

Zhang, Q., \& Seto, K. C. (2011). Mapping urbanization dynamics at regional and global scales using multi-temporal DMSP/OLS nighttime light data. Remote Sensing of Environment, 115(9), $2320-2329$.

Zhang, Q., \& Seto, K. C. (2013). Can night-time light data identify typologies of urbanization? A global assessment of successes and failures. Remote Sensing, 5(7), 3476-3494.

[dataset] ICF. 2004-2017. Demographic and Health Surveys (various) [Datasets]. Funded by USAID. Rockville, Maryland: ICF [Distributor].

[dataset] SWAC/OECD (2018). Africapolis. SWAC-E geopolis. Africapolis.org 


\section{APPENDIX}

Figure A1 | Distribution of raw nightlight data and inverse hyperbolic sine nightlights for Africapolis urban households in our sample
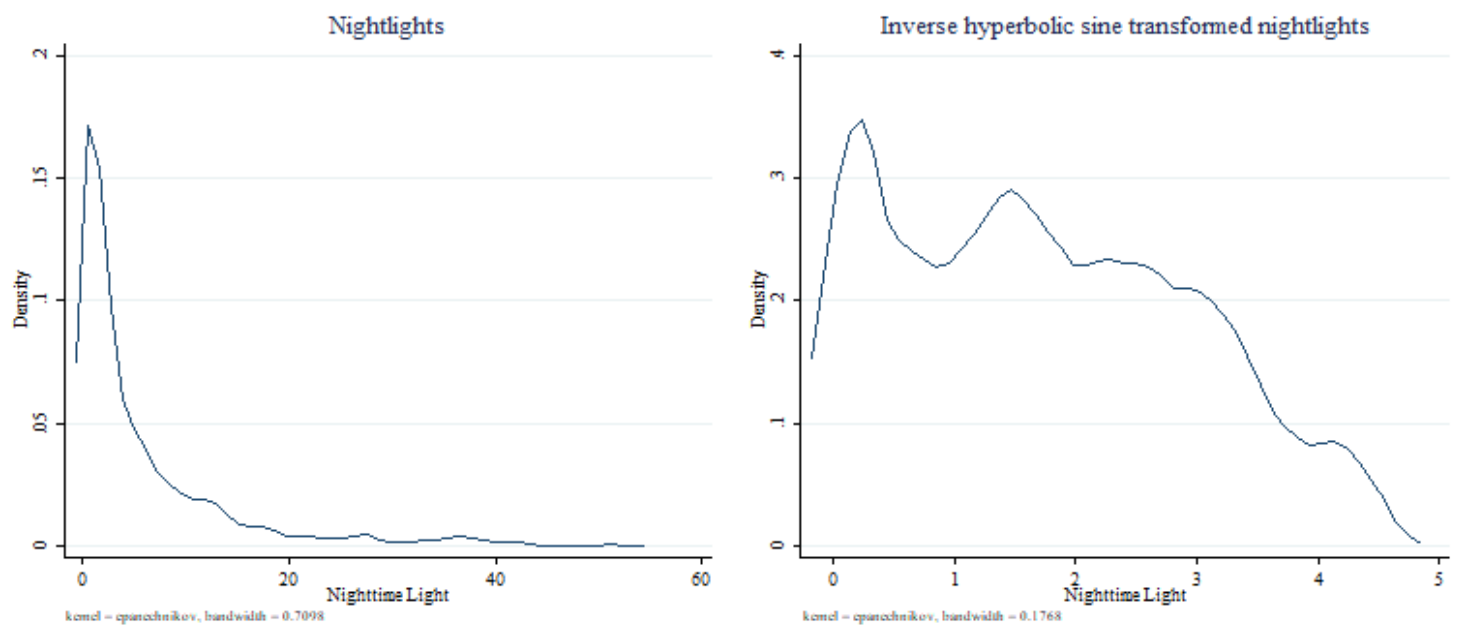

Source: 2015 DHS geophysical data for Burundi, Kenya, Ethiopia, Malawi, Mozambique, Rwanda, Tanzania, Uganda, Zambia and Zimbabwe.

Note: 11,566 urban observations as defined by children living in regions included in the Africapolis dataset

Figure A2 | Probability a child is stunted and nighttime lights, for Africapolis urban sample only

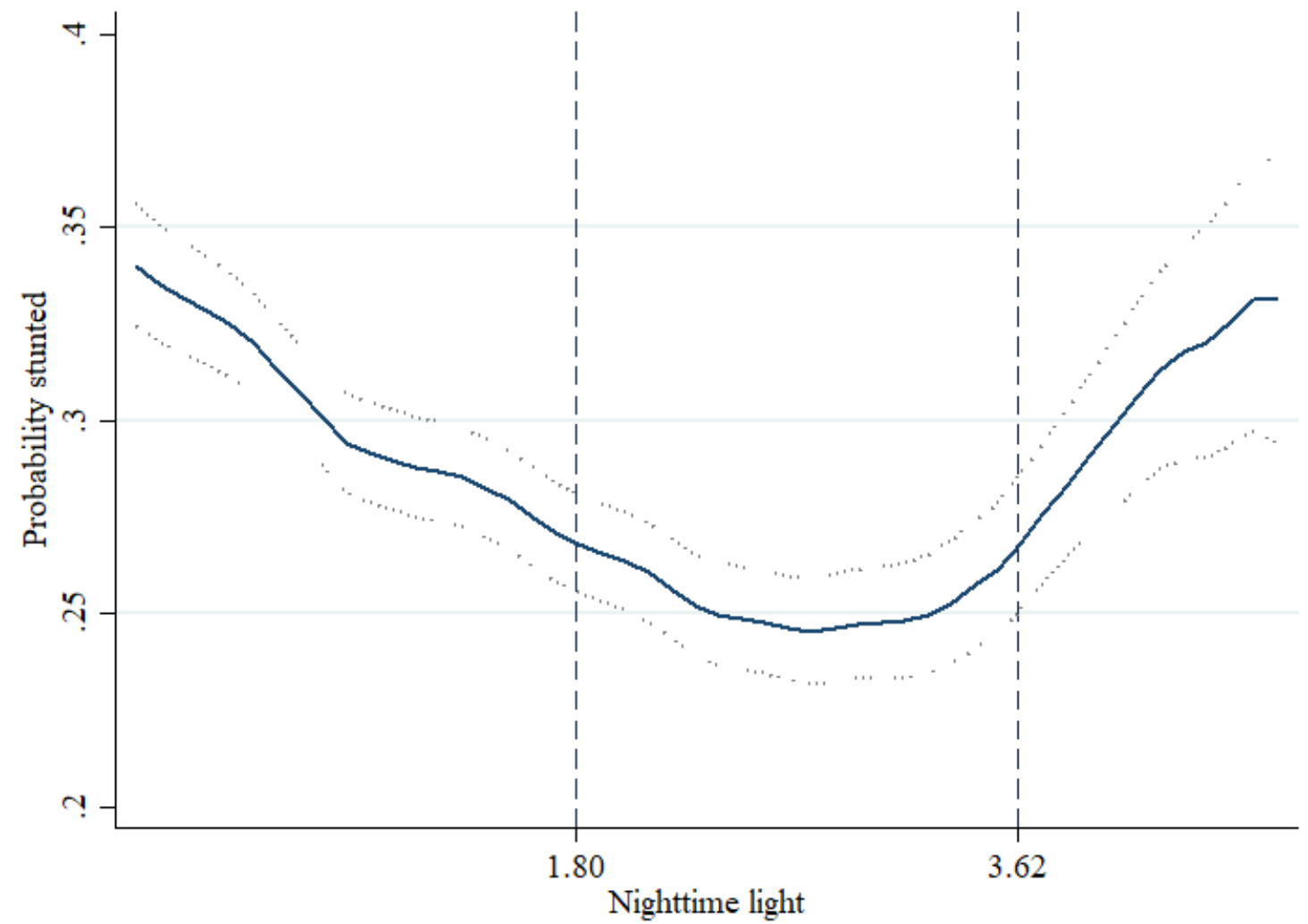

Source: 2015 DHS data for Burundi, Kenya, Ethiopia, Malawi, Mozambique, Rwanda, Tanzania, Uganda, Zambia and Zimbabwe.

Note: The nonparametric regressions are estimated through an Epanechnikov kernel function using a rule-of-thumb bandwidth estimator. The dotted lines around the plot represent the $90 \%$ confidence interval. The y-axes do not start at zero for better rendition of the graph. $N=40,324$ 
Figure A3 | Probability a child is stunted and log population

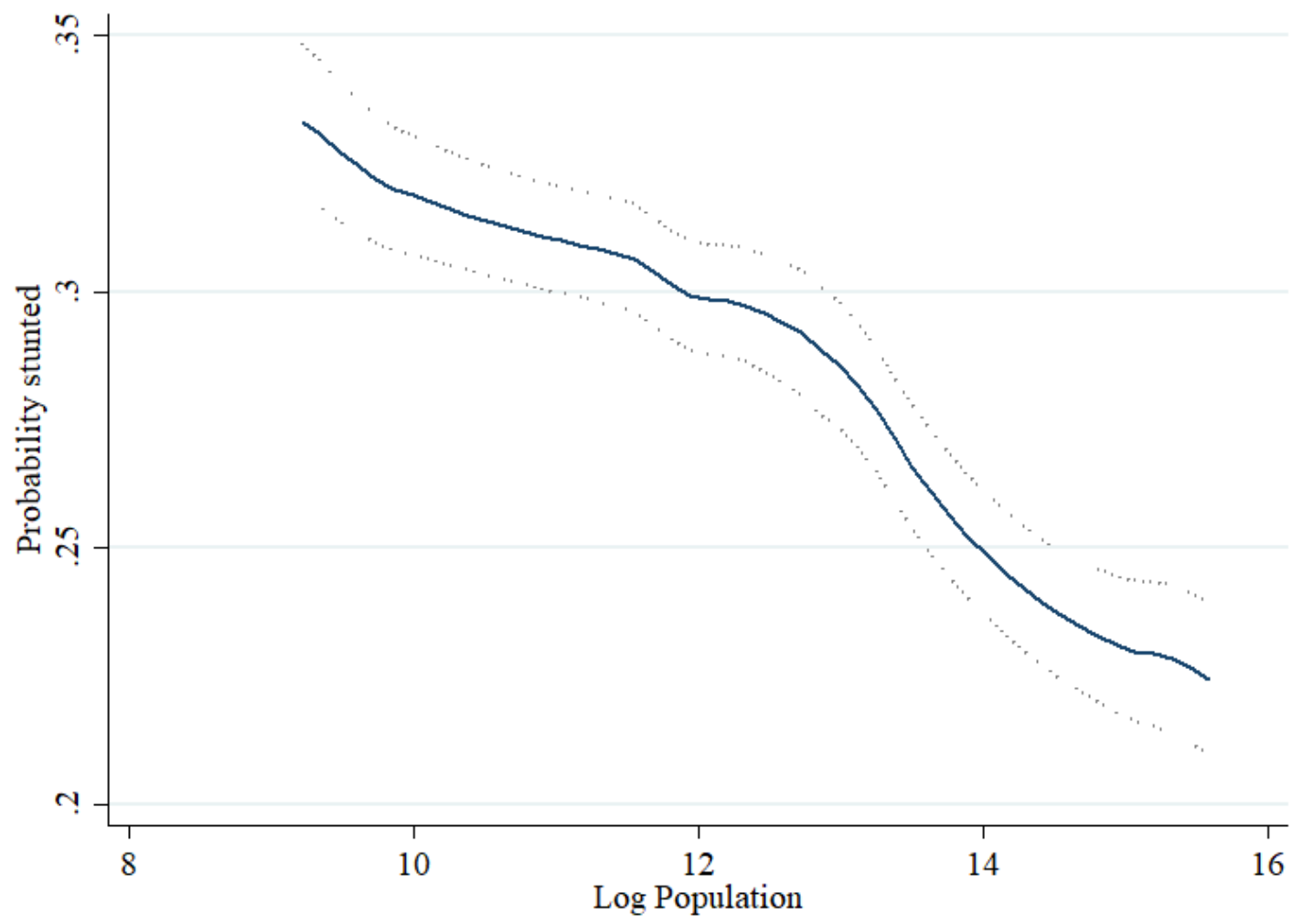

Source: 2015 DHS data for Burundi, Kenya, Ethiopia, Malawi, Mozambique, Rwanda, Tanzania, Uganda, Zambia and Zimbabwe.

Note: The nonparametric regressions are estimated through an Epanechnikov kernel function using a rule-of-thumb bandwidth estimator. The dotted lines around the plot represent the $90 \%$ confidence interval. The y-axes do not start at zero for better rendition of the graph. $N=40,324$

Figure A4 | Child wasting and anaemia levels
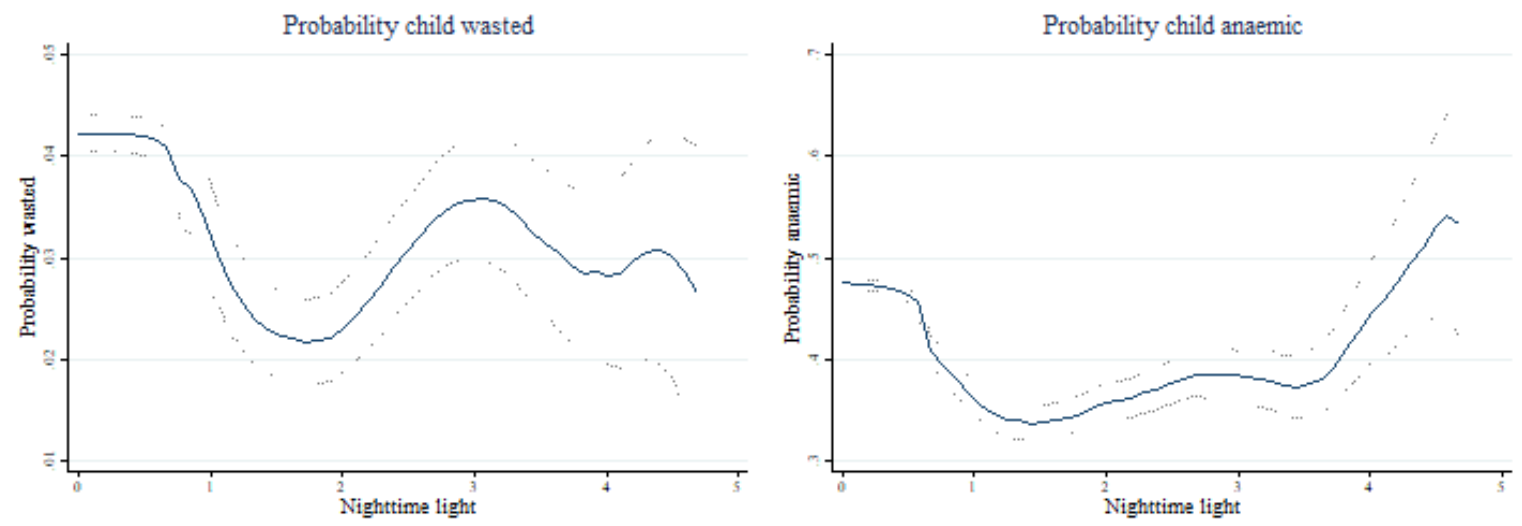

Source: 2015 DHS data for Burundi, Kenya, Ethiopia, Malawi, Mozambique, Rwanda, Tanzania, Uganda, Zambia and Zimbabwe.

Note: The nonparametric regressions are estimated through an Epanechnikov kernel function using a rule-of-thumb bandwidth estimator. The dotted lines around the plot represent the $90 \%$ confidence interval. The y-axes do not start at zero for better rendition of the graph. $N=40,324$ 
Figure A5 | Urbanization and determinants of child stunting, Kenya and Zambia
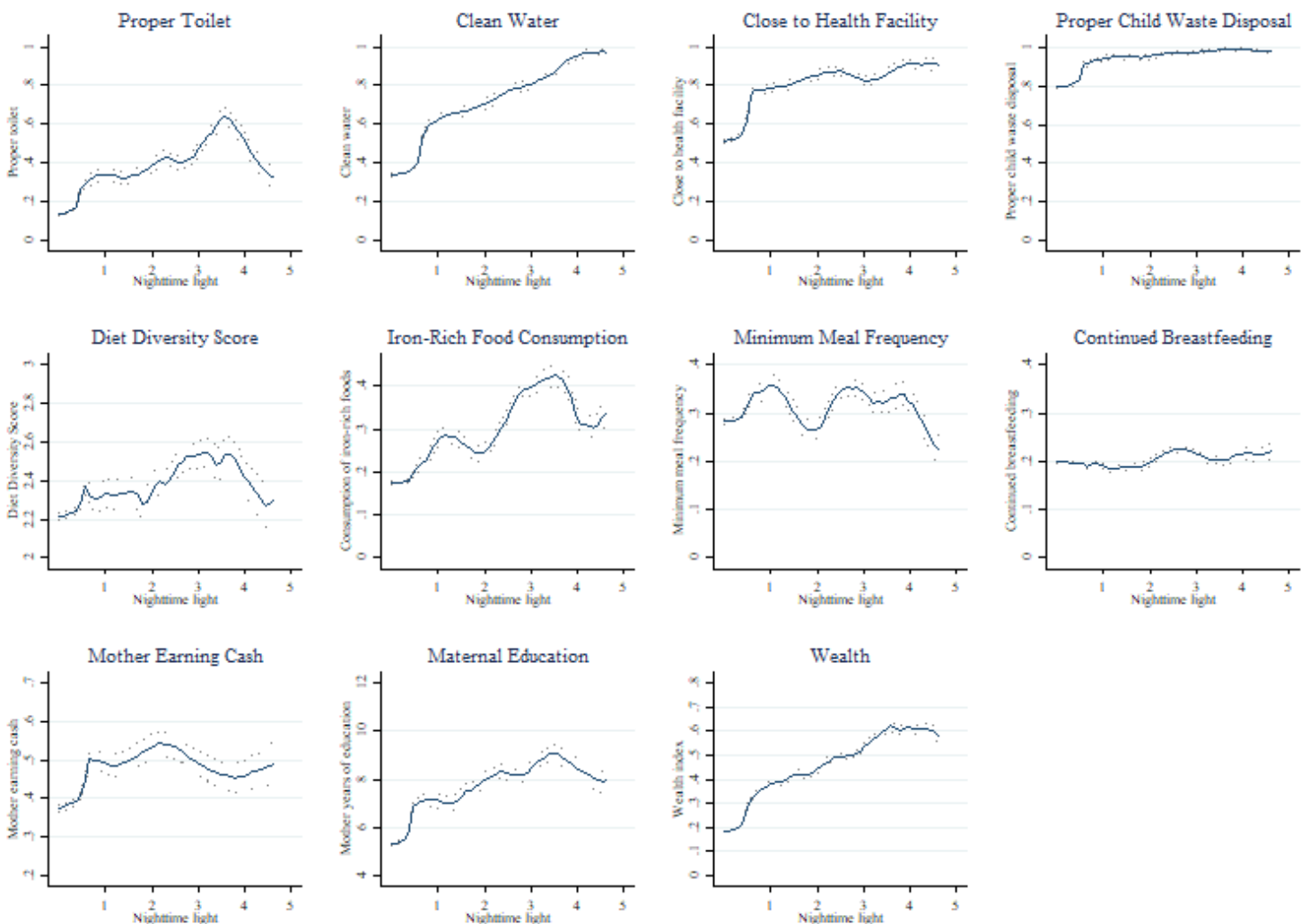

Source: 2015 DHS data for Burundi, Kenya, Ethiopia, Malawi, Mozambique, Rwanda, Tanzania, Uganda, Zambia and Zimbabwe.

Note: The nonparametric regressions are estimated through an Epanechnikov kernel function using a rule-of-thumb bandwidth estimator. The dotted lines around the plot represent the $90 \%$ confidence interval. The y-axes do not start at zero for better rendition of the graph. $N=40,324$ 
Figure A6 | Urbanization and determinants of child stunting, other countries
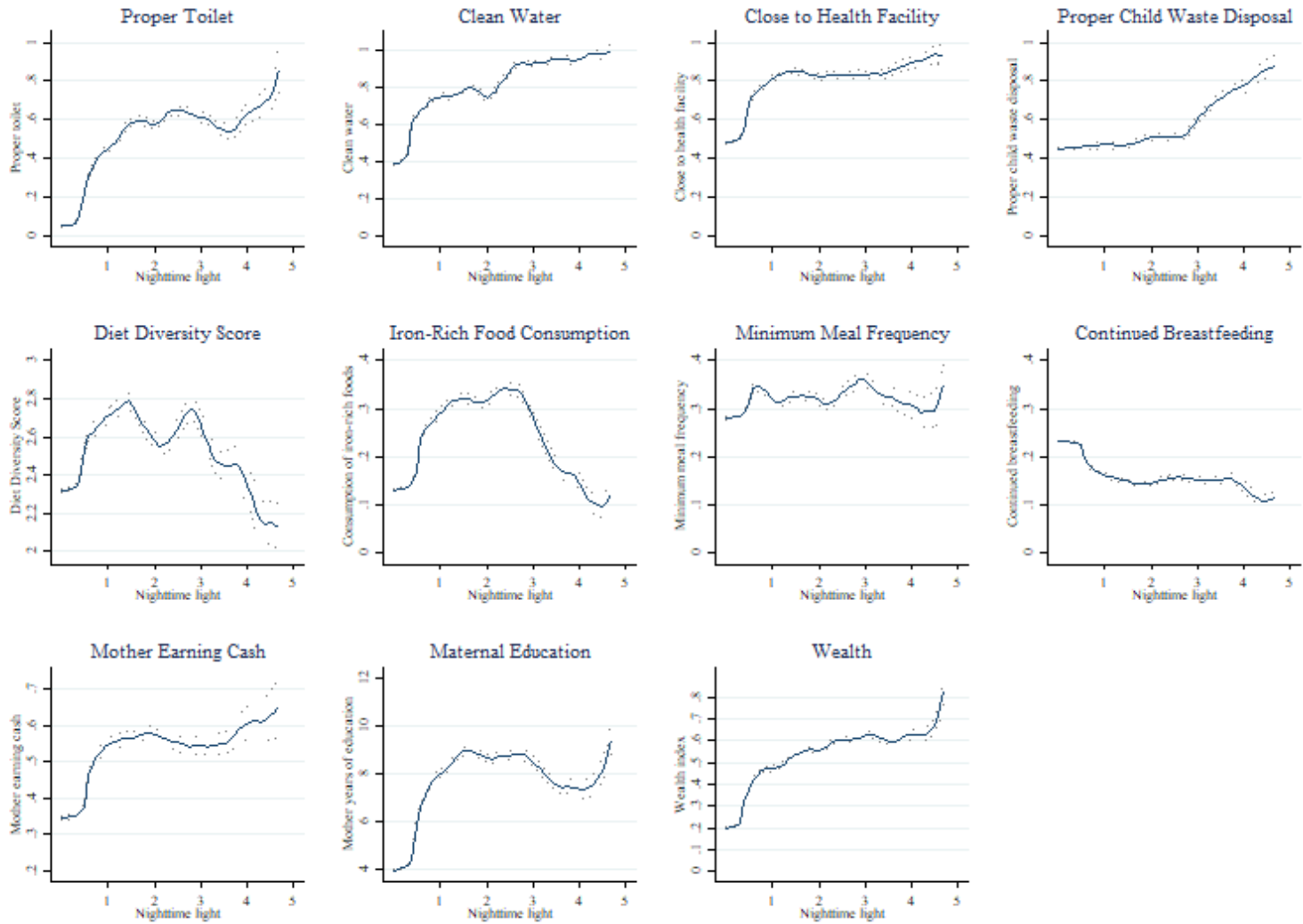

Source: 2015 DHS data for Burundi, Kenya, Ethiopia, Malawi, Mozambique, Rwanda, Tanzania, Uganda, Zambia and Zimbabwe.

Note: The nonparametric regressions are estimated through an Epanechnikov kernel function using a rule-of-thumb bandwidth estimator. The dotted lines around the plot represent the $90 \%$ confidence interval. The y-axes do not start at zero for better rendition of the graph. $N=40,324$ 
Table A1 | Regression results for child stunting and nighttime lights, per country

\begin{tabular}{|c|c|c|c|c|c|c|c|c|c|c|c|}
\hline VARIABLES & $\begin{array}{c}(1) \\
\text { Total } \\
\end{array}$ & $\begin{array}{c}(2) \\
\text { Burundi }\end{array}$ & $\begin{array}{c}\text { (3) } \\
\text { Ethiopia }\end{array}$ & $\begin{array}{c}(4) \\
\text { Kenya } \\
\end{array}$ & $\begin{array}{c}(5) \\
\text { Malawi } \\
\end{array}$ & $\begin{array}{c}(6) \\
\text { Mozambique }\end{array}$ & $\begin{array}{c}\text { (7) } \\
\text { Rwanda }\end{array}$ & $\begin{array}{c}(8) \\
\text { Tanzania } \\
\end{array}$ & $\begin{array}{c}(9) \\
\text { Uganda }\end{array}$ & $\begin{array}{c}(10) \\
\text { Zambia } \\
\end{array}$ & $\begin{array}{c}(11) \\
\text { Zimbabwe } \\
\end{array}$ \\
\hline $\begin{array}{l}\text { Panel A: } \\
\operatorname{Dark}(0-1.80) \text { vs NL > } 1.80\end{array}$ & $\begin{array}{l}-0.161 * * * \\
(0.00896)\end{array}$ & $\begin{array}{c}-0.506 * * * \\
(0.0960)\end{array}$ & $\begin{array}{c}-0.250 * * * \\
(0.0343)\end{array}$ & $\begin{array}{c}-0.108 * * * \\
(0.0296)\end{array}$ & $\begin{array}{c}-0.188 * * * \\
(0.0450)\end{array}$ & $\begin{array}{c}-0.192 * * * \\
(0.0200)\end{array}$ & $\begin{array}{c}-0.265 * * * \\
(0.0356)\end{array}$ & $\begin{array}{c}-0.214 * * * \\
(0.0283)\end{array}$ & $\begin{array}{c}-0.205 * * * \\
(0.0566)\end{array}$ & $\begin{array}{c}-0.0873 * * * \\
(0.0177)\end{array}$ & $\begin{array}{c}-0.109 * * * \\
(0.0175)\end{array}$ \\
\hline $\begin{array}{l}\text { Observations } \\
\text { R-squared }\end{array}$ & $\begin{array}{c}40,324 \\
0.011 \\
\end{array}$ & $\begin{array}{l}3,250 \\
0.006 \\
\end{array}$ & $\begin{array}{l}4,692 \\
0.007 \\
\end{array}$ & $\begin{array}{l}4,429 \\
0.007 \\
\end{array}$ & $\begin{array}{l}2,523 \\
0.012 \\
\end{array}$ & $\begin{array}{l}4,969 \\
0.019 \\
\end{array}$ & $\begin{array}{l}1,828 \\
0.017 \\
\end{array}$ & $\begin{array}{l}4,641 \\
0.017 \\
\end{array}$ & $\begin{array}{l}2,096 \\
0.007 \\
\end{array}$ & $\begin{array}{l}6,492 \\
0.006 \\
\end{array}$ & $\begin{array}{l}5,404 \\
0.008 \\
\end{array}$ \\
\hline $\begin{array}{l}\text { Panel B: } \\
\text { Dark (NL } 0-1.80) \text { vs Bright ( > } \\
\text { 3.62) }\end{array}$ & $0.0662 * * *$ & $0.506 * * *$ & $0.286 * * *$ & $0.0713^{*}$ & $0.170 * * *$ & $0.278 * * *$ & $0.233 * * *$ & $0.249 * * *$ & $0.248 * * *$ & 0.0438 & $0.125 * * *$ \\
\hline $\begin{array}{l}\text { Medium Dark (NL } 1.80-2.40 \text { ) } \\
\text { vs Bright ( > 3.62) }\end{array}$ & $\begin{array}{c}-0.111^{* * * *} \\
(0.0268)\end{array}$ & & $\begin{array}{c}0.0731 \\
(0.0835)\end{array}$ & $\begin{array}{c}-0.152 * * * \\
(0.0525)\end{array}$ & $\begin{array}{l}-0.0654 \\
(0.0859)\end{array}$ & $\begin{array}{l}0.205^{* * *} \\
(0.0501)\end{array}$ & $\begin{array}{l}-0.0250 \\
(0.0829)\end{array}$ & $\begin{array}{c}0.0818 \\
(0.0550)\end{array}$ & $\begin{array}{l}0.0553 \\
(0.104)\end{array}$ & $\begin{array}{c}-0.0998 * * \\
(0.0402)\end{array}$ & $\begin{array}{c}0.0387 \\
(0.0317)\end{array}$ \\
\hline $\begin{array}{l}\text { Medium (NL } 2.40-3.01) \text { vs } \\
\text { Bright ( > 3.62) }\end{array}$ & $\begin{array}{c}-0.136 * * * \\
(0.0264)\end{array}$ & & $\begin{array}{c}0.0788 \\
(0.0852)\end{array}$ & $\begin{array}{l}-0.0588 \\
(0.0648)\end{array}$ & & $\begin{array}{c}0.0589 \\
(0.0470)\end{array}$ & $\begin{array}{l}-0.0696 \\
(0.0870)\end{array}$ & & $\begin{array}{l}0.0736 \\
(0.136)\end{array}$ & $\begin{array}{l}-0.0537 \\
(0.0414)\end{array}$ & \\
\hline $\begin{array}{l}\text { Medium Bright (NL } 3.01 \text { - } \\
\text { 3.62) vs Bright (> 3.62) }\end{array}$ & $\begin{array}{c}-0.0923 * * * \\
(0.0294)\end{array}$ & & & & & $\begin{array}{l}0.0516 \\
(0.0377)\end{array}$ & & & & $\begin{array}{l}-0.0756^{*} \\
(0.0429)\end{array}$ & \\
\hline Observations & 40,324 & 3,250 & 4,692 & 4,429 & 2,523 & 4,969 & 1,828 & 4,641 & 2,096 & 6,492 & 5,404 \\
\hline R-squared & 0.013 & 0.006 & 0.007 & 0.010 & 0.012 & 0.022 & 0.017 & 0.017 & 0.007 & 0.008 & 0.008 \\
\hline
\end{tabular}


Table A2 | Regression results for child stunting and nighttime lights, Table 3 Panel A full regressions

\begin{tabular}{|c|c|c|c|c|c|c|c|}
\hline VARIABLES & $\begin{array}{c}\text { (1) } \\
\text { Nighttime } \\
\text { lights } \\
\end{array}$ & $\begin{array}{c}\text { (2) } \\
\text { Controls } \\
\end{array}$ & $\begin{array}{c}\text { (3) } \\
\text { Health Inputs } \\
\end{array}$ & $\begin{array}{c}\text { (4) } \\
\text { Feeding } \\
\text { practices }\end{array}$ & $\begin{array}{c}\text { (5) } \\
\text { Maternal } \\
\text { characteristics }\end{array}$ & $\begin{array}{c}\text { (6) } \\
\text { Wealth } \\
\end{array}$ & $\begin{array}{c}\text { (7) } \\
\text { All variables } \\
\end{array}$ \\
\hline $\begin{array}{l}\text { Dark }(0-1.80) \\
\text { vs NL > } 1.80\end{array}$ & $\begin{array}{l}0.161 * * * \\
(0.00896)\end{array}$ & $\begin{array}{l}0.147 * * * \\
(0.00881)\end{array}$ & $\begin{array}{c}0.0797 * * * \\
(0.0101)\end{array}$ & $\begin{array}{l}0.135 * * * \\
(0.00904)\end{array}$ & $\begin{array}{c}0.0902 * * * \\
(0.00929)\end{array}$ & $\begin{array}{c}0.0113 \\
(0.0107)\end{array}$ & $\begin{array}{l}0.00164 \\
(0.0108)\end{array}$ \\
\hline $\begin{array}{l}\text { Controls } \\
\text { Household size }\end{array}$ & & $\begin{array}{l}0.000386 \\
(0.00115)\end{array}$ & $\begin{array}{l}-0.000592 \\
(0.00115)\end{array}$ & $\begin{array}{l}0.000570 \\
(0.00115)\end{array}$ & $\begin{array}{l}-0.000906 \\
(0.00115)\end{array}$ & $\begin{array}{l}9.92 \mathrm{e}-05 \\
(0.00115)\end{array}$ & $\begin{array}{c}-0.000895 \\
(0.00116)\end{array}$ \\
\hline Age mother & & $\begin{array}{c}-0.00238 * * * \\
(0.000458)\end{array}$ & $\begin{array}{c}-0.00225 * * * \\
(0.000459)\end{array}$ & $\begin{array}{c}-0.00245 * * * \\
(0.000458)\end{array}$ & $\begin{array}{c}-0.00338 * * * \\
(0.000459)\end{array}$ & $\begin{array}{c}-0.00205 * * * \\
(0.000456)\end{array}$ & $\begin{array}{c}-0.00285 * * * \\
(0.000461)\end{array}$ \\
\hline $\begin{array}{l}\text { Male } \\
\text { Household } \\
\text { Head (dummy) }\end{array}$ & & $\begin{array}{l}-0.0124 * \\
(0.00683)\end{array}$ & $\begin{array}{l}-0.0137 * * \\
(0.00681)\end{array}$ & $\begin{array}{l}-0.0125 * \\
(0.00684)\end{array}$ & $\begin{array}{c}-0.0147 * * \\
(0.00678)\end{array}$ & $\begin{array}{l}-0.00588 \\
(0.00677)\end{array}$ & $\begin{array}{c}-0.0105 \\
(0.00677)\end{array}$ \\
\hline $\begin{array}{l}\text { Sanitation and } \\
\text { Healthcare } \\
\text { Accessible } \\
\text { health facility } \\
\text { (dummy) }\end{array}$ & & & $\begin{array}{c}-0.0271 * * * \\
(0.00621)\end{array}$ & & & & $\begin{array}{l}-0.00707 \\
(0.00623)\end{array}$ \\
\hline $\begin{array}{l}\text { Proper toilet } \\
\text { (dummy) }\end{array}$ & & & $\begin{array}{c}-0.0721 * * * \\
(0.00869)\end{array}$ & & & & $\begin{array}{l}0.000461 \\
(0.00952)\end{array}$ \\
\hline $\begin{array}{l}\text { Clean water } \\
\text { (dummy) }\end{array}$ & & & $\begin{array}{c}-0.0571 * * * \\
(0.00652)\end{array}$ & & & & $\begin{array}{c}-0.0296 * * * \\
(0.00659)\end{array}$ \\
\hline $\begin{array}{l}\text { Proper waste } \\
\text { disposal } \\
\text { (dummy) }\end{array}$ & & & $\begin{array}{c}0.0112 * \\
(0.00676)\end{array}$ & & & & $\begin{array}{l}0.0169 * * \\
(0.00672)\end{array}$ \\
\hline $\begin{array}{l}\text { Feeding } \\
\text { practices } \\
\text { Diet diversity } \\
\text { score (cluster } \\
\text { level) }\end{array}$ & & & & $\begin{array}{l}0.00573 * \\
(0.00313)\end{array}$ & & & $\begin{array}{c}0.00876 * * * \\
(0.00310)\end{array}$ \\
\hline $\begin{array}{l}\text { Iron-rich food } \\
\text { consumption } \\
\text { (cluster level) }\end{array}$ & & & & $\begin{array}{c}-0.0773 * * * \\
(0.0147)\end{array}$ & & & $\begin{array}{l}-0.0231 \\
(0.0146)\end{array}$ \\
\hline $\begin{array}{l}\text { Minimum meal } \\
\text { frequency } \\
\text { (cluster level) }\end{array}$ & & & & $\begin{array}{c}-0.0242 * * \\
(0.0113)\end{array}$ & & & $\begin{array}{l}-0.0124 \\
(0.0111)\end{array}$ \\
\hline $\begin{array}{l}\text { Continued } \\
\text { breastfeeding } \\
\text { (cluster level) }\end{array}$ & & & & $\begin{array}{c}0.108 * * * \\
(0.0216)\end{array}$ & & & $\begin{array}{c}0.0575 * * * \\
(0.0216)\end{array}$ \\
\hline $\begin{array}{l}\text { Maternal } \\
\text { characteristics } \\
\text { Mother earning } \\
\text { cash (dummy) }\end{array}$ & & & & & $\begin{array}{c}0.00386 \\
(0.00622)\end{array}$ & & $\begin{array}{c}0.0113 * \\
(0.00624)\end{array}$ \\
\hline $\begin{array}{l}\text { Years of } \\
\text { education } \\
\text { (mother) }\end{array}$ & & & & & $\begin{array}{l}-0.0181 * * * \\
(0.000838)\end{array}$ & & $\begin{array}{l}-0.0122 * * * \\
(0.000932)\end{array}$ \\
\hline Wealth index & & & & & & $\begin{array}{c}-0.388 * * * \\
(0.0163)\end{array}$ & $\begin{array}{c}-0.261 * * * \\
(0.0207)\end{array}$ \\
\hline $\begin{array}{l}\text { Age, sex and } \\
\text { country } \\
\text { dummies }\end{array}$ & & $\mathrm{x}$ & $\mathrm{x}$ & $x$ & $x$ & $\mathrm{X}$ & $\mathrm{x}$ \\
\hline Constant & $\begin{array}{l}0.266 * * * \\
(0.00837)\end{array}$ & $\begin{array}{l}0.417 * * * \\
(0.0243)\end{array}$ & $\begin{array}{l}0.521 * * * \\
(0.0264)\end{array}$ & $\begin{array}{l}0.415 * * * \\
(0.0257)\end{array}$ & $\begin{array}{c}0.609 * * * \\
(0.0258)\end{array}$ & $\begin{array}{c}0.625 * * * \\
(0.0257)\end{array}$ & $\begin{array}{c}0.677 * * * \\
(0.0284)\end{array}$ \\
\hline Observations & 40,324 & 40,324 & 40,324 & 40,324 & 40,324 & 40,324 & 40,324 \\
\hline R-squared & 0.011 & 0.064 & 0.070 & 0.065 & 0.078 & 0.079 & 0.086 \\
\hline
\end{tabular}

Robust standard errors in parentheses

$* * * \mathrm{p}<0.01, * * \mathrm{p}<0.05, * \mathrm{p}<0.1$ 
Table A3 | Regression results for child stunting and nighttime lights, Table 3 Panel B full regressions

\begin{tabular}{|c|c|c|c|c|c|c|c|}
\hline VARIABLES & $\begin{array}{l}\text { (1) } \\
\text { Nighttime } \\
\text { lights } \\
\end{array}$ & $\begin{array}{c}\text { (2) } \\
\text { Controls } \\
\end{array}$ & $\begin{array}{c}\text { (3) } \\
\text { Health Inputs } \\
\end{array}$ & $\begin{array}{c}\text { (4) } \\
\text { Feeding } \\
\text { practices } \\
\end{array}$ & $\begin{array}{c}\text { (5) } \\
\text { Maternal } \\
\text { characteristics } \\
\end{array}$ & $\begin{array}{c}\text { (6) } \\
\text { Wealth }\end{array}$ & $\begin{array}{c}\text { (7) } \\
\text { All variables }\end{array}$ \\
\hline $\begin{array}{l}\text { Dark }(0-1.80) \text { vs } \\
\text { Bright }(>3.62)\end{array}$ & $\begin{array}{c}0.0876 * * * \\
(0.0214)\end{array}$ & $\begin{array}{c}0.0931 * * * \\
(0.0212)\end{array}$ & $\begin{array}{c}0.0214 \\
(0.0219)\end{array}$ & $\begin{array}{l}0.0848 * * * \\
(0.0214)\end{array}$ & $\begin{array}{l}0.0378 * \\
(0.0212)\end{array}$ & $\begin{array}{c}-0.0634 * * * \\
(0.0223)\end{array}$ & $\begin{array}{c}-0.0684 * * * \\
(0.0223)\end{array}$ \\
\hline $\begin{array}{l}\text { Medium }(1.80- \\
3.62) \text { vs Bright (> } \\
3.62)\end{array}$ & $\begin{array}{c}-0.0945 * * * \\
(0.0230)\end{array}$ & $\begin{array}{c}-0.0687 * * * \\
(0.0227)\end{array}$ & $\begin{array}{c}-0.0738 * * * \\
(0.0228)\end{array}$ & $\begin{array}{c}-0.0636^{* * * *} \\
(0.0228)\end{array}$ & $\begin{array}{c}-0.0667 * * * \\
(0.0224)\end{array}$ & $\begin{array}{c}-0.0929 * * * \\
(0.0226)\end{array}$ & $\begin{array}{c}-0.0873 * * * \\
(0.0225)\end{array}$ \\
\hline $\begin{array}{l}\text { Controls } \\
\text { Household size }\end{array}$ & & $\begin{array}{l}0.000386 \\
(0.00115)\end{array}$ & $\begin{array}{l}-0.000590 \\
(0.00115)\end{array}$ & $\begin{array}{l}0.000568 \\
(0.00115)\end{array}$ & $\begin{array}{l}-0.000906 \\
(0.00115)\end{array}$ & $\begin{array}{l}9.52 \mathrm{e}-05 \\
(0.00115)\end{array}$ & $\begin{array}{l}-0.000885 \\
(0.00116)\end{array}$ \\
\hline Age mother & & $\begin{array}{c}-0.00238 * * * \\
(0.000458)\end{array}$ & $\begin{array}{c}-0.00226 * * * \\
(0.000459)\end{array}$ & $\begin{array}{c}-0.00245 * * * \\
(0.000458)\end{array}$ & $\begin{array}{c}-0.00338 * * * \\
(0.000459)\end{array}$ & $\begin{array}{c}-0.00204 * * * \\
(0.000456)\end{array}$ & $\begin{array}{r}-0.00284 * * * \\
(0.000460)\end{array}$ \\
\hline $\begin{array}{l}\text { Male Household } \\
\text { Head (dummy) }\end{array}$ & & $\begin{array}{l}-0.0128^{*} \\
(0.00683)\end{array}$ & $\begin{array}{l}-0.0142 * * \\
(0.00681)\end{array}$ & $\begin{array}{l}-0.0129 * \\
(0.00683)\end{array}$ & $\begin{array}{l}-0.0151 * * \\
(0.00678)\end{array}$ & $\begin{array}{l}-0.00631 \\
(0.00677)\end{array}$ & $\begin{array}{c}-0.0109 \\
(0.00677)\end{array}$ \\
\hline $\begin{array}{l}\text { Sanitation and } \\
\text { Healthcare } \\
\text { Accessible health } \\
\text { facility (dummy) }\end{array}$ & & & $\begin{array}{c}-0.0276 * * * \\
(0.00621)\end{array}$ & & & & $\begin{array}{l}-0.00749 \\
(0.00624)\end{array}$ \\
\hline $\begin{array}{l}\text { Proper toilet } \\
\text { (dummy) }\end{array}$ & & & $\begin{array}{c}-0.0705 * * * \\
(0.00868)\end{array}$ & & & & $\begin{array}{c}0.00341 \\
(0.00949)\end{array}$ \\
\hline $\begin{array}{l}\text { Clean water } \\
\text { (dummy) }\end{array}$ & & & $\begin{array}{c}-0.0583 * * * \\
(0.00653)\end{array}$ & & & & $\begin{array}{c}-0.0307 * * * \\
(0.00660)\end{array}$ \\
\hline $\begin{array}{l}\text { Proper waste } \\
\text { disposal (dummy) }\end{array}$ & & & $\begin{array}{c}0.0107 \\
(0.00676)\end{array}$ & & & & $\begin{array}{l}0.0164 * * \\
(0.00672)\end{array}$ \\
\hline $\begin{array}{l}\text { Feeding } \\
\text { practices } \\
\text { Diet diversity } \\
\text { score (cluster } \\
\text { level) }\end{array}$ & & & & $\begin{array}{l}0.00581 * \\
(0.00313)\end{array}$ & & & $\begin{array}{c}0.00888 * * * \\
(0.00310)\end{array}$ \\
\hline $\begin{array}{l}\text { Iron-rich food } \\
\text { consumption } \\
\text { (cluster level) }\end{array}$ & & & & $\begin{array}{c}-0.0764 * * * \\
(0.0147)\end{array}$ & & & $\begin{array}{l}-0.0214 \\
(0.0146)\end{array}$ \\
\hline $\begin{array}{l}\text { Minimum meal } \\
\text { frequency } \\
\text { (cluster level) }\end{array}$ & & & & $\begin{array}{c}-0.0238 * * \\
(0.0113)\end{array}$ & & & $\begin{array}{l}-0.0119 \\
(0.0111)\end{array}$ \\
\hline $\begin{array}{l}\text { Continued } \\
\text { breastfeeding } \\
\text { (cluster level) }\end{array}$ & & & & $\begin{array}{c}0.106 * * * \\
(0.0217)\end{array}$ & & & $\begin{array}{c}0.0546^{* * *} \\
(0.0216)\end{array}$ \\
\hline $\begin{array}{l}\text { Maternal } \\
\text { characteristics } \\
\text { Mother earning } \\
\text { cash (dummy) }\end{array}$ & & & & & $\begin{array}{c}0.00389 \\
(0.00621)\end{array}$ & & $\begin{array}{c}0.0114 * \\
(0.00623)\end{array}$ \\
\hline $\begin{array}{l}\text { Years of } \\
\text { education } \\
\text { (mother) }\end{array}$ & & & & & $\begin{array}{c}-0.0181 * * * \\
(0.000837)\end{array}$ & & $\begin{array}{r}-0.0121 * * * \\
(0.000930)\end{array}$ \\
\hline Wealth index & & & & & & $\begin{array}{c}-0.393 * * * \\
(0.0163)\end{array}$ & $\begin{array}{c}-0.268 * * * \\
(0.0207)\end{array}$ \\
\hline $\begin{array}{l}\text { Age, sex and } \\
\text { country dummies }\end{array}$ & & $\mathrm{x}$ & $\mathrm{x}$ & $\mathrm{X}$ & $\mathrm{X}$ & $\mathrm{x}$ & $\mathrm{x}$ \\
\hline Constant & $\begin{array}{c}0.340 * * * \\
(0.0212)\end{array}$ & $\begin{array}{c}0.468 * * * \\
(0.0307)\end{array}$ & $\begin{array}{c}0.577 * * * \\
(0.0327)\end{array}$ & $\begin{array}{c}0.462 * * * \\
(0.0318)\end{array}$ & $\begin{array}{c}0.659 * * * \\
(0.0317)\end{array}$ & $\begin{array}{c}0.696 * * * \\
(0.0320)\end{array}$ & $\begin{array}{c}0.745 * * * \\
(0.0343)\end{array}$ \\
\hline $\begin{array}{l}\text { Observations } \\
\text { R-squared }\end{array}$ & $\begin{array}{c}40,324 \\
0.012\end{array}$ & $\begin{array}{c}40,324 \\
0.064\end{array}$ & $\begin{array}{c}40,324 \\
0.071\end{array}$ & $\begin{array}{c}40,324 \\
0.066\end{array}$ & $\begin{array}{c}40,324 \\
0.078\end{array}$ & $\begin{array}{c}40,324 \\
0.080\end{array}$ & $\begin{array}{c}40,324 \\
0.087\end{array}$ \\
\hline
\end{tabular}

Robust standard errors in parentheses

$* * * \mathrm{p}<0.01, * * \mathrm{p}<0.05, * \mathrm{p}<0.1$ 
Table A4 | Regression results for child stunting and nighttime lights, other countries

\begin{tabular}{|c|c|c|c|c|c|c|c|}
\hline & (1) & (2) & (3) & (4) & $(5)$ & (6) & (7) \\
\hline VARIABLES & $\begin{array}{c}\text { Nighttime } \\
\text { lights }\end{array}$ & Controls & $\begin{array}{c}\text { Healthcare access } \\
\text { and sanitation }\end{array}$ & Feeding practices & $\begin{array}{c}\text { Maternal } \\
\text { characteristics }\end{array}$ & Wealth & All variables \\
\hline \multicolumn{8}{|l|}{ Panel A: } \\
\hline Dark $(0-1.80)$ vs NL $>1.80$ & $\begin{array}{r}0.216^{* * *} \\
(0.0105)\end{array}$ & $\begin{array}{c}0.185 * * * \\
(0.0105)\end{array}$ & $\begin{array}{l}0.103 * * * \\
(0.0122)\end{array}$ & $\begin{array}{l}0.168 * * * \\
(0.0108)\end{array}$ & $\begin{array}{c}0.118^{* * *} \\
(0.0111)\end{array}$ & $\begin{array}{c}0.0386 * * * \\
(0.0127)\end{array}$ & $\begin{array}{c}0.0259 * * \\
(0.0129)\end{array}$ \\
\hline Observations & 29,403 & 29,403 & 29,403 & 29,403 & 29,403 & 29,403 & 29,403 \\
\hline R-squared & 0.015 & 0.069 & 0.078 & 0.072 & 0.086 & 0.087 & 0.095 \\
\hline \multicolumn{8}{|l|}{ Panel B: } \\
\hline Dark $(0-1.80)$ vs Bright $(>3.62)$ & $\begin{array}{r}0.220 * * * \\
(0.0278)\end{array}$ & $\begin{array}{c}0.257 * * * \\
(0.0279)\end{array}$ & $\begin{array}{l}0.152 * * * \\
(0.0288)\end{array}$ & $\begin{array}{l}0.244 * * * \\
(0.0281)\end{array}$ & $\begin{array}{l}0.172 * * * \\
(0.0275)\end{array}$ & $\begin{array}{l}0.0701 * * \\
(0.0286)\end{array}$ & $\begin{array}{l}0.0526 * \\
(0.0285)\end{array}$ \\
\hline Medium (1.80 - 3.62) vs Bright (> 3.62) & $\begin{array}{l}0.00460 \\
(0.0294)\end{array}$ & $\begin{array}{c}0.0785^{* * *} * \\
(0.0294)\end{array}$ & $\begin{array}{l}0.0534 * \\
(0.0293)\end{array}$ & $\begin{array}{c}0.0829 * * * \\
(0.0296)\end{array}$ & $\begin{array}{c}0.0576 * * \\
(0.0285)\end{array}$ & $\begin{array}{c}0.0338 \\
(0.0287)\end{array}$ & $\begin{array}{c}0.0286 \\
(0.0285)\end{array}$ \\
\hline Observations & 29,403 & 29,403 & 29,403 & 29,403 & 29,403 & 29,403 & 29,403 \\
\hline R-squared & 0.015 & 0.070 & 0.078 & 0.072 & 0.086 & 0.087 & 0.095 \\
\hline \multicolumn{8}{|l|}{ Controls } \\
\hline Basic controls & & $\mathrm{x}$ & $\mathrm{x}$ & $\mathrm{x}$ & $\mathrm{x}$ & $\mathrm{x}$ & $\mathrm{x}$ \\
\hline Healthcare access and sanitation & & & $\mathrm{x}$ & & & & $\mathrm{x}$ \\
\hline Feeding practices & & & & $\mathrm{x}$ & & & $\mathrm{x}$ \\
\hline Maternal characteristics & & & & & $\mathrm{x}$ & & $\mathrm{x}$ \\
\hline Wealth & & & & & & $\mathrm{x}$ & $\mathrm{x}$ \\
\hline
\end{tabular}

Wealth

*** $\mathrm{p}<0.01, * * \mathrm{p}<0.05, * \mathrm{p}<0.1$

Note: Linear probability model explaining child stunting and urbanization. Basic controls include mother's age, whether household head is male, household size and a full set of dummies for gender, age (in months) and country. Healthcare access and sanitation includes four dummies on whether the household has an accessible health facility, a proper toilet (defined by having a flushing system or ventilated improved latrine), clean water (defined by piped into the dwelling or plot, coming from a public tap or tube well, a tanker truck or bottled water), disposes of child waste properly (defined by flushing waste down a toilet or latrine or thrown into the garbage). Feeding practices are based on cluster levels averages. They include a diet diversity score (1-7), iron-rich food consumption, minimum meal frequency and continued breastfeeding after 12 months of age. Maternal characteristics include a dummy on mother earning in cash and years of formal education of the mother. Wealth is represented by a wealth index calculated by a multiple correspondence analysis using household assets (electricity, radio, television, refrigerator, bicycle, motorcycle, car/truck, tile/concrete floor, metal roof, cement walls and non-wood cooking fuel). 
Table A5 | Regression results for child stunting and nighttime lights, Zambia and Kenya only

\begin{tabular}{|c|c|c|c|c|c|c|c|}
\hline & (1) & (2) & (3) & (4) & (5) & (6) & (7) \\
\hline VARIABLES & $\begin{array}{l}\text { Nighttime } \\
\text { lights }\end{array}$ & Controls & $\begin{array}{c}\text { Healthcare access } \\
\text { and sanitation }\end{array}$ & Feeding practices & $\begin{array}{c}\text { Maternal } \\
\text { characteristics }\end{array}$ & Wealth & All variables \\
\hline \multicolumn{8}{|l|}{ Panel A: } \\
\hline Dark $(0-1.80)$ vs NL > 1.80 & $\begin{array}{c}0.0695^{* * * *} \\
(0.0153)\end{array}$ & $\begin{array}{c}0.0974 * * * \\
(0.0150)\end{array}$ & $\begin{array}{c}0.0479 * * * \\
(0.0171)\end{array}$ & $\begin{array}{c}0.0897 * * * \\
(0.0154)\end{array}$ & $\begin{array}{c}0.0591 * * * \\
(0.0158)\end{array}$ & $\begin{array}{l}-0.0120 \\
(0.0189)\end{array}$ & $\begin{array}{l}-0.0223 \\
(0.0191)\end{array}$ \\
\hline Observations & 10,921 & 10,921 & 10,921 & 10,921 & 10,921 & 10,921 & 10,921 \\
\hline R-squared & 0.004 & 0.048 & 0.052 & 0.049 & 0.058 & 0.059 & 0.065 \\
\hline \multicolumn{8}{|l|}{ Panel B: } \\
\hline Dark $(0-1.80)$ vs Bright $(>3.62)$ & $\begin{array}{c}0.0202 \\
(0.0259)\end{array}$ & $\begin{array}{l}0.0485^{*} \\
(0.0254)\end{array}$ & $\begin{array}{l}-0.00642 \\
(0.0269)\end{array}$ & $\begin{array}{c}0.0418 \\
(0.0256)\end{array}$ & $\begin{array}{c}0.0125 \\
(0.0256)\end{array}$ & $\begin{array}{c}-0.0764 * * * \\
(0.0286)\end{array}$ & $\begin{array}{c}-0.0870^{* * *} \\
(0.0288)\end{array}$ \\
\hline Medium (1.80 - 3.62) vs Bright (> 3.62) & $\begin{array}{c}-0.0820 * * * * \\
(0.0300)\end{array}$ & $\begin{array}{c}-0.0811 * * * \\
(0.0292)\end{array}$ & $\begin{array}{c}-0.0880 * * * \\
(0.0292)\end{array}$ & $\begin{array}{c}-0.0800 * * * \\
(0.0293)\end{array}$ & $\begin{array}{c}-0.0777 * * * \\
(0.0289)\end{array}$ & $\begin{array}{c}-0.100^{* * *} \\
(0.0292)\end{array}$ & $\begin{array}{c}-0.100 * * * \\
(0.0292)\end{array}$ \\
\hline Observations & 10,921 & 10,921 & 10,921 & 10,921 & 10,921 & 10,921 & 10,921 \\
\hline R-squared & 0.005 & 0.049 & 0.054 & 0.051 & 0.059 & 0.062 & 0.067 \\
\hline \multicolumn{8}{|l|}{ Controls } \\
\hline Basic controls & & $\mathrm{x}$ & $\mathrm{x}$ & $\mathrm{x}$ & $\mathrm{x}$ & $\mathrm{x}$ & $\mathrm{x}$ \\
\hline Healthcare access and sanitation & & & $\mathrm{x}$ & & & & $\mathrm{x}$ \\
\hline Feeding practices & & & & $\mathrm{x}$ & & & $\mathrm{x}$ \\
\hline Maternal characteristics & & & & & $\mathrm{x}$ & & $\mathrm{x}$ \\
\hline Wealth & & & & & & $\mathrm{x}$ & $\mathrm{x}$ \\
\hline
\end{tabular}

Robust standard errors in parentheses

$* * * \mathrm{p}<0.01, * * \mathrm{p}<0.05, * \mathrm{p}<0.1$

Note: Linear probability model explaining child stunting and urbanization. Basic controls include mother's age, whether household head is male, household size and a full set of dummies for gender, age (in months) and country. Healthcare access and sanitation includes four dummies on whether the household has an accessible health facility, a proper toilet (defined by having a flushing system or ventilated improved latrine), clean water (defined by piped into the dwelling or plot, coming from a public tap or tube well, a tanker truck or bottled water), disposes of child waste properly (defined by flushing waste down a toilet or latrine or thrown into the garbage). Feeding practices are based on cluster levels averages. They include a diet diversity score (1-7), iron-rich food consumption, minimum meal frequency and continued breastfeeding after 12 months of age. Maternal characteristics include a dummy on mother earning in cash and years of formal education of the mother. Wealth is represented by a wealth index calculated by a multiple correspondence analysis using household assets (electricity, radio, television, refrigerator, bicycle, motorcycle, car/truck, tile/concrete floor, metal roof, cement walls and non-wood cooking fuel). 
Table A6 | Regression results for child stunting and nighttime lights, per wealth category

\begin{tabular}{|c|c|c|c|c|c|c|}
\hline VARIABLES & $\begin{array}{c}\text { (1) } \\
\text { Nighttime } \\
\text { lights }\end{array}$ & $\begin{array}{c}(2) \\
\text { Controls }\end{array}$ & $\begin{array}{c}\text { (3) } \\
\text { Health } \\
\text { Inputs }\end{array}$ & $\begin{array}{c}\text { (4) } \\
\text { Feeding } \\
\text { practices }\end{array}$ & $\begin{array}{c}\text { (5) } \\
\text { Maternal } \\
\text { characteristics }\end{array}$ & $\begin{array}{c}(7) \\
\text { All } \\
\text { variables }\end{array}$ \\
\hline $\begin{array}{l}\text { Panel A: Poorest } 25 \% \\
\text { Dark }(0-1.80) \text { vs Bright (> } \\
\text { 3.62) }\end{array}$ & $\begin{array}{c}0.122 \\
(0.134)\end{array}$ & $\begin{array}{c}0.115 \\
(0.131)\end{array}$ & $\begin{array}{c}0.112 \\
(0.130)\end{array}$ & $\begin{array}{c}0.107 \\
(0.133)\end{array}$ & $\begin{array}{l}0.0848 \\
(0.135)\end{array}$ & $\begin{array}{l}0.0759 \\
(0.137)\end{array}$ \\
\hline $\begin{array}{l}\text { Medium }(1.80-3.62) \text { vs } \\
\text { Bright }(>3.62)\end{array}$ & $\begin{array}{c}0.119 \\
(0.143)\end{array}$ & $\begin{array}{c}0.108 \\
(0.139)\end{array}$ & $\begin{array}{c}0.113 \\
(0.138)\end{array}$ & $\begin{array}{c}0.107 \\
(0.141)\end{array}$ & $\begin{array}{c}0.108 \\
(0.143)\end{array}$ & $\begin{array}{c}0.110 \\
(0.145)\end{array}$ \\
\hline $\begin{array}{l}\text { Observations } \\
\text { R-squared }\end{array}$ & $\begin{array}{c}12,179 \\
0.055\end{array}$ & $\begin{array}{c}12,179 \\
0.057\end{array}$ & $\begin{array}{c}12,179 \\
0.058\end{array}$ & $\begin{array}{c}12,179 \\
0.059\end{array}$ & $\begin{array}{c}12,179 \\
0.061\end{array}$ & $\begin{array}{c}12,179 \\
0.063\end{array}$ \\
\hline $\begin{array}{l}\text { Panel B: Poor-mid 25\% } \\
\text { Dark }(0-1.80) \text { vs Bright (> } \\
3.62)\end{array}$ & $\begin{array}{l}-0.0117 \\
(0.220)\end{array}$ & $\begin{array}{l}-0.0120 \\
(0.220)\end{array}$ & $\begin{array}{l}-0.0390 \\
(0.222)\end{array}$ & $\begin{array}{l}-0.0147 \\
(0.231)\end{array}$ & $\begin{array}{l}-0.0224 \\
(0.206)\end{array}$ & $\begin{array}{l}-0.0469 \\
(0.219)\end{array}$ \\
\hline $\begin{array}{l}\text { Medium }(1.80-3.62) \text { vs } \\
\text { Bright }(>3.62)\end{array}$ & $\begin{array}{l}-0.0281 \\
(0.227)\end{array}$ & $\begin{array}{l}-0.0304 \\
(0.227)\end{array}$ & $\begin{array}{l}-0.0461 \\
(0.228)\end{array}$ & $\begin{array}{l}-0.0308 \\
(0.237)\end{array}$ & $\begin{array}{l}-0.0288 \\
(0.213)\end{array}$ & $\begin{array}{l}-0.0435 \\
(0.225)\end{array}$ \\
\hline $\begin{array}{l}\text { Observations } \\
\text { R-squared }\end{array}$ & $\begin{array}{l}8,425 \\
0.055\end{array}$ & $\begin{array}{l}8,425 \\
0.055\end{array}$ & $\begin{array}{l}8,425 \\
0.056\end{array}$ & $\begin{array}{l}8,425 \\
0.058\end{array}$ & $\begin{array}{l}8,425 \\
0.058\end{array}$ & $\begin{array}{l}8,425 \\
0.062\end{array}$ \\
\hline $\begin{array}{l}\text { Panel C: Mid-rich } \mathbf{2 5 \%} \\
\text { Dark }(0-1.80) \text { vs Bright (> } \\
\text { 3.62) }\end{array}$ & $\begin{array}{l}-0.0737 \\
(0.0722)\end{array}$ & $\begin{array}{l}-0.0793 \\
(0.0724)\end{array}$ & $\begin{array}{c}-0.111 \\
(0.0741)\end{array}$ & $\begin{array}{l}-0.0804 \\
(0.0726)\end{array}$ & $\begin{array}{l}-0.0600 \\
(0.0711)\end{array}$ & $\begin{array}{l}-0.0869 \\
(0.0727)\end{array}$ \\
\hline $\begin{array}{l}\text { Medium }(1.80-3.62) \text { vs } \\
\text { Bright }(>3.62)\end{array}$ & $\begin{array}{l}-0.130 * \\
(0.0765)\end{array}$ & $\begin{array}{l}-0.133 * \\
(0.0766)\end{array}$ & $\begin{array}{l}-0.141 * \\
(0.0779)\end{array}$ & $\begin{array}{l}-0.128 * \\
(0.0769)\end{array}$ & $\begin{array}{c}-0.107 \\
(0.0753)\end{array}$ & $\begin{array}{c}-0.111 \\
(0.0765)\end{array}$ \\
\hline $\begin{array}{l}\text { Observations } \\
\text { R-squared }\end{array}$ & $\begin{array}{l}9,741 \\
0.061\end{array}$ & $\begin{array}{l}9,741 \\
0.062\end{array}$ & $\begin{array}{l}9,741 \\
0.065\end{array}$ & $\begin{array}{l}9,741 \\
0.063\end{array}$ & $\begin{array}{l}9,741 \\
0.069\end{array}$ & $\begin{array}{l}9,741 \\
0.073\end{array}$ \\
\hline $\begin{array}{l}\text { Panel D: Richest } \mathbf{2 5 \%} \\
\text { Dark }(0-1.80) \text { vs Bright (> } \\
\text { 3.62) }\end{array}$ & $\begin{array}{l}0.00541 \\
(0.0237)\end{array}$ & $\begin{array}{l}0.00386 \\
(0.0237)\end{array}$ & $\begin{array}{l}-0.0296 \\
(0.0244)\end{array}$ & $\begin{array}{l}0.00432 \\
(0.0238)\end{array}$ & $\begin{array}{l}-0.0101 \\
(0.0236)\end{array}$ & $\begin{array}{l}-0.0293 \\
(0.0243)\end{array}$ \\
\hline $\begin{array}{l}\text { Medium }(1.80-3.62) \text { vs } \\
\text { Bright }(>3.62)\end{array}$ & $\begin{array}{c}-0.0765 * * * \\
(0.0242)\end{array}$ & $\begin{array}{c}-0.0765 * * * \\
(0.0241)\end{array}$ & $\begin{array}{c}-0.0803 * * * \\
(0.0242)\end{array}$ & $\begin{array}{c}-0.0753 * * * \\
(0.0242)\end{array}$ & $\begin{array}{c}-0.0720 * * * \\
(0.0239)\end{array}$ & $\begin{array}{c}-0.0777 * * * \\
(0.0241)\end{array}$ \\
\hline $\begin{array}{l}\text { Observations } \\
\text { R-squared }\end{array}$ & $\begin{array}{l}9,979 \\
0,052\end{array}$ & $\begin{array}{l}9,979 \\
0.056\end{array}$ & $\begin{array}{l}9,979 \\
0,062\end{array}$ & $\begin{array}{l}9,979 \\
0,057\end{array}$ & $\begin{array}{l}9,979 \\
0071\end{array}$ & $\begin{array}{l}9,979 \\
0074\end{array}$ \\
\hline Controls & & & & & & \\
\hline $\begin{array}{l}\text { Basic controls } \\
\text { Healthcare access and } \\
\text { sanitation }\end{array}$ & & $\mathrm{x}$ & $\begin{array}{l}\mathrm{x} \\
\mathrm{x}\end{array}$ & $\mathrm{x}$ & $\mathrm{x}$ & $\begin{array}{l}\mathrm{x} \\
\mathrm{x}\end{array}$ \\
\hline Feeding practices & & & & $\mathrm{x}$ & & $\mathrm{x}$ \\
\hline Maternal characteristics & & & & & $\mathrm{x}$ & $\mathrm{x}$ \\
\hline Wealth & & & & & & $\mathrm{X}$ \\
\hline
\end{tabular}

Robust standard errors in parentheses

$* * * \mathrm{p}<0.01, * * \mathrm{p}<0.05, * \mathrm{p}<0.1$

Note: Linear probability model explaining child stunting and urbanization. Basic controls include mother's age, whether household head is male, household size and a full set of dummies for gender, age (in months) and country. Healthcare access and sanitation includes four dummies on whether the household has an accessible health facility, a proper toilet (defined by having a flushing system or ventilated improved latrine), clean water (defined by piped into the dwelling or plot, coming from a public tap or tube well, a tanker truck or bottled water), disposes of child waste properly (defined by flushing waste down a toilet or latrine or thrown into the garbage). Feeding practices are based on cluster levels averages. They include a diet diversity score (1-7), iron-rich food consumption, minimum meal frequency and continued breastfeeding after 12 months of age. Maternal characteristics include a dummy on mother earning in cash and years of formal education of the mother. Wealth is represented by a wealth index calculated by a multiple correspondence analysis using household assets (electricity, radio, television, refrigerator, bicycle, motorcycle, car/truck, tile/concrete floor, metal roof, cement walls and non-wood cooking fuel). 